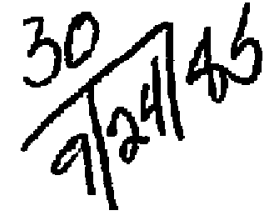

SLAC-PUB -3727

DE85 018112

SLAC-PUB - 3727

July 1985

(I)

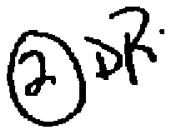

\title{
HIGH RESOLUTION DRIFT CHAMBERS *
}

\author{
J. VA'VRA \\ Stanford Linear Aceelerator Center \\ Stanford Univeraity, Stanford, California, 84905
}

\begin{abstract}
High precision drift chambers capable of achieving $\leq 50 \mu m$ resolutions are discussed. In partieular, we compare so called cool and hat gases, various charge collection geometries, several timing techniques and we also discuss some systematic problems. We also present what we would consider an "ultimaten design of the vartex ehamber.
\end{abstract}

Extended version of paper presented at the

S. Miniato Meeting on Future High Energy Machines, Florence, Italy, May 22-25, 1984.

Aleo submitted to Nuclear Instrumenta and Methodu

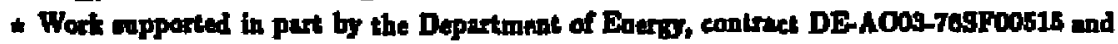
b) CaRH 


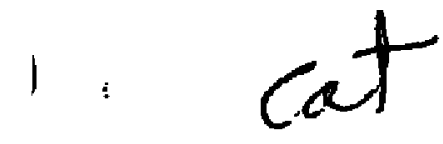

\section{$\cos =-8405241-5$}

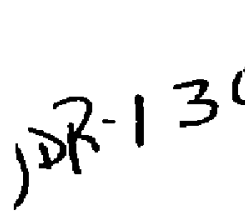

\section{Introduction}

High precision drift chambers will play an important part of high enercy experiments for the foreseedble future. This is primarily bectuse they can be built large enough to have sufficient redundancy with existing technologies and still be financially accessible. Single track resolution of $20-50 \mu \mathrm{m}$ for $1 \mathrm{~cm}$ of drift and double track resolution of about 100-600 $\mu \mathrm{m}$ seems to be pousible. There has been aubstantial progress in recent years mainly in the following areas:

1. Improvemene in tunderstanding low diffusion gases both experimentalty and through model ealculations.

2. Introduction of new collection optics arrangements.

3. Improvements of the electronies by introduction of:

(a) low noise front end hybrid amplifiers and

(b) fust ( $\geq 100 \mathrm{MHz}$ ) digitizers.

A. Improvements in understanding the detection process vis the introduction of detailed computer simulation programs.

5. Introduction of new technology (Be beam pipea, carbon fiber, high precision machining).

This talk reviews these improvementu and tries to present a judgment whether some of these goals are sctually achievable and under what conditions. In particular we diacuss a choice between so called "cool" and "hot" gased and various charge collectlon arrangements. We also roview the present undentanding of a comparison of the leading edge and the center of gravity timing.

Many aspects, however, are not discussed and ve refer the reader to a recent review of this subject by G. Charpal and F. Sauti [1]. 


\section{Theoretical Diseussion}

We present two methods to entionte drift chamber renclution. The first method iz aimplo and clearly tranparent, bowerer, it does not neceanarily provide - rufficient insight into the details of the detection procea. With this method we

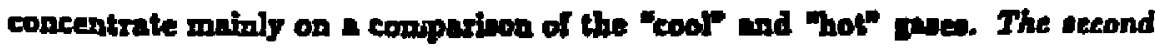
method is Monte Curlo simulation, which is wifortunately mech less traneparent, neverthelea it is probably the onl way to helude a oufiteiont amount of detail mbout the detection proces involving en fintricate imterploy of mny vuriables. Here ane murt exercies a careful judgment about what effects are important to include.

\subsection{SDAPLE METHOD}

In this method one unually separate the lodividual contribations to the final tracking resolution as follows (acplecting the ryatematic ersor contributions for the moment):

$$
\sigma^{2}=\sigma_{\text {digules }}+\sigma_{\text {odiration }}+\sigma_{\text {track }}^{2}
$$

The track width contribution otnek is gnerally negligible if we make our anclyais insensitive to the presence of energetic electrond by rejecting off-track samples and if we neglect the fact that the resulting reoldual distributions are not truly gaussian. The of malnefion term ia composed of two contributions. The finat contribution comes fram an occational presence of very large ianization clunters (Landav effect) and the second one comes from the fluctuatlon in finite ionisation statinsica, both contrlbutions coupled with the ponivochronous charge collection of the typieal drift cells. The relative size of the firot two terms in eq. (1) generally dependy on the choice of gas, electronica, method of charge collection and the methad of data malysis. As we will see later elther term can donglate dopending on the particular case. 


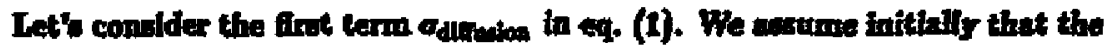
diffucion is opherically ogmmetric. Bued on Binatein theury one clectron time dispension of an original poist-like churge distribution in $\sigma_{2}(1$ electron $)=\sqrt{2 D}$, where $t$ is the drift time and $D$ in the diffulon coufficient. Thin ean be rewritten as $\sigma_{n}(1$ dectron $)=\sqrt{2 \epsilon_{k} X / A \bar{B}}=\sqrt{\left(2 \epsilon_{k} X\right) /(E / p)} \times 1 / \sqrt{p}$ where $e_{k}$ is the electron characteriatle energ, $E$ is the doctrite feld, $p$ is the prenure and $X$ is the drift dintance. From this we can see two unoful and practical dependencied. For a range of operation whern $\epsilon_{4} \sim$ const and $X \sim$ cosat, $\sigma_{a}(1$ electron $) \sim 1 / \sqrt{E}$, and $f(x)=$ case where $E / p \sim$ conut we get $\sigma_{k}(1$ election $) \sim 1 / \sqrt{p}$ uince $f_{0}$ in $E / p$ dependent. Finally, becanse of the diffuion dependence on the dintanes, the resolution date are ususlly fitted with $\theta^{2}=\sigma_{6}^{6}+6 \cdot 2$ function.

Now we lstroduce a definition of a cool ga a a case where $E_{k}=k T$, where $k$ is the Boltzman constant and $T$ in the temperature of the gar. If the ges operates within this limit, wa call It a thermal limit operstion, and $\sigma_{z}(1$ electron $)=\sqrt{2 k T X / e E}$. An example of a cool ga la CO. Figure 1 indicates that somewhere ar.und $E \sim 2 \mathrm{kV} / \mathrm{em}$ and 1 atm of pressore, the drifting electrons begin to be keated and $\sigma_{x}(1$ olectron) departs from the thermal limit. This Illustrates the reed to tune the cool gaves for an optimum operatine point. Figure 2 indicates an example of such tuning for thres examples of the coolgases. One can conclude that at the optimum, one can schieve $\sigma_{4}$ (1 electron) $\sim$ s0$80 \mu \mathrm{m}$ at $1 \mathrm{~atm}$ of presaure for $1 \mathrm{~cm}$ of drift. One should point out that another feature of the cool ganes in that the drift velocity has a linear dependence on the electric field $E$ and the gas denaity $N$, aamely

$$
V_{\mathrm{drin}}=\frac{1}{2} \frac{a}{m}\left(\frac{E}{N}\right) \frac{1}{(\sigma 0)}
$$

where $m$ is the electson mass, $a$ is itu charge, $\sigma$ is the momentum trangfer crousaectlon and $O$ is the menn electron velocity [2]. The drift velocity of the cool gavas in slow becauso of a large value of the momentum transfer cross section, i.e., the gas uppears to be viscous to the drifting electrons. 
By comparison, the typical gases used in drift chambers todny begin to be hot at rather low values of the electric field gredient, w can be aeen in the example of fig. 3. Typically, we can parametrize the increase of the electron chanacteristic enercy as $t_{k} \sim(\Sigma / p)^{a}$. The typical single electron diffusion in hot gaturea can be seen in fig. 4. In tuch ganes one could parametrize the single electron diffusion as

$$
\sigma_{R}(1 \text { electron })=\sigma_{x}^{0} \sqrt{\left(\frac{E}{p}\right)^{\alpha} \frac{X}{E}} \quad \text { for } E>E_{\varepsilon}
$$

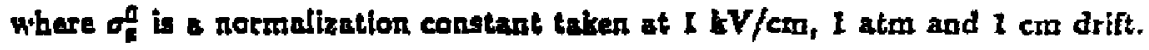
Typically, one has $\sigma_{2}^{0} \sim 180-600 \mu m$, l.e., a rother large value.

So far we havo anaumed the difuslon to be spherically sy rometric. In many hot gases thls assunption is not valid, and one finds thut ie longitudinal diffuslon $\sigma_{2}$ ean be two to four 1 lmes smaller than the trartsverse diffusion $\sigma_{x}$. Figute 5 Indleates one cxanns's, where $\sigma_{L}\left(1\right.$ electron) $\sim 250 \mu \mathrm{m} \sim 1 / 2 \sigma_{*}(1$ electron) normalized for 1 atrr, $1 \mathrm{~cm}$ of drin, $1 \mathrm{kV} / \mathrm{cm}$ electric field and asing the JADE gas [3]. Recently there has been progreas in calculating these two diffusion paramaten for typleal gases where the momentum transfer cross-sections are known [35]. Figure 6 lliwatrates one example of such a caleulation [4] for $90 \% \mathrm{Ar}+10 \%$ $\mathrm{C}_{1} \mathrm{E}_{10}$, where one reaches $\sigma_{\mathrm{L}}(1$ electron) $\sim 125 \mu \mathrm{m}$ at 1 atm and $1 \mathrm{~cm}$ of drift If one chocses the electric fleld $E \sim 1.5-2.0 \mathrm{kV} / \mathrm{cm}$, i.e., a factor of four reduction wes raslized corppared to the transverse diffusion. As we will gee leter, this result slightly underestimates the author's results in the microjet thamber. In addition, there appeass to be some disagreement between the measurement (see 6g. 5) and the calculation (Nee 6ga. 6 and 26), although the explanation could be either in a slight diterence in the gares ured or because at larger electric fieldo tho experimental cross-sections used in the calculation [4] are lesa reliable for thls particular mixtare.

Another exanple of indirect evidence that one can achieve oL(1 elextronj $~ *$

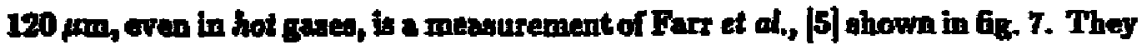


have measured the tracking recolution to be about $60 \mathrm{~mm}$ at $1 \mathrm{ktm}$ and $1 \mathrm{~cm}$ of

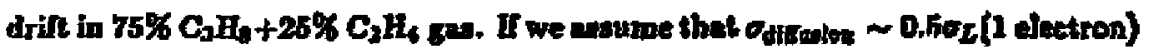
(this point will bo explainad later) and that their electronice contribution is negligible, we conclude $\sigma_{L}(1$ electrou) $\sim 120 \mu m$ for this gas.

We conelude that in the present cool gases one ean achieve or (1 electson) $\sim$ $50-80 \mu \mathrm{m}$ and in the best hot gases one could obtain ${ }_{2}(1$ electron) $\sim 120-200 \mathrm{pm}$ for $1 \mathrm{~cm}$ of drift and 1 alm pressure.

The next quation is how do we obtain odifneias frow a knowledge of $\sigma_{z}(1$ clectron) or oL $(1$ electron). Thin genarally depends on the method of astection of the signal.

\section{Leading Edge Timing}

T'he leadir.6 edge timing generally samples only a sadl traction of the full track tample length because of the nature of eharge collection geomety in typical drift chambers (aee next chapter). This means that not all of the total $N$ charga clustera arriving at the anode will actually be takep into necount. Some of the clusters arrive so late that they casnot contribute to the lending edge timlng. In addition, we can assume that $\eta \cdot N \cdot p \cdot n$ in the fraction of the aumber of dectron having a chance to contribute to the landing edge tiging, whare $\eta$ is a monoure of efficiency of the charge collection for this particular timing mathod and can be estimated from the Monte Carrlo program [T] by plotting a histogram almills to fig. 10 and determining an effective samplo size, $p$ is the preasure and $n$ is an average number of electrons per cluster. In general, n can be tnilueneed by many variables as for instance by the total gain on the anode (later atriving charge can be suppreased by saturation effectu), the particular choice of the charge collectins geometry, the choice of gan, and a choie: of the operating point. From puraly statistical consideration [6] for the firat electron timing we would get (if wa keep $E / p$ constant as we change the presature $p$ and $\eta \cdot N \cdot p \cdot n$ is larg);

$$
\sigma_{\text {dlanion }} \sim \frac{0.91}{\sqrt{\ln (\eta \bar{N} m)}} \frac{\sigma_{L}(1 \text { electron })}{\sqrt{p}} .
$$


For typical examples, we get $F=0.91 / \sqrt{\ln (\eta N p m)} \sim 0.5$ (wee table 5). The logarithmic dependence in eq. (2) reduces the oensitivity to errors in the estimate of the number of clusters contributing to the timing. One can see that the fastest way to improve the resolution is to increase the preasure. To improve the Iesolution through an improvement of the collection optics (n) is a much siower way to gain. From table 5 one can conclude that the leading edge timing data can be explained using eq. (2), certainly at the level of difference of about 10-20 $\mu \mathrm{m}$. To understand the data below this level will require a careful understanding of systematic errors.

This means that for the cool gases one can achicve $\sigma_{\text {diftulon }} \sim 10-20 \mu \mathrm{m}$ at 4 atm and $1 \mathrm{~cm}$ of drift. In contrast, in the best hot gasea one could achieve $\sigma_{\text {difumion }} \sim 30-50 \mu \mathrm{m}$ under the same conditions, i.e., to match the result of the cool gases we have to go to higher preasure.

\section{Center of Gravity Timing}

Let's assume that our electronics (say $100 \mathrm{MHz}$ FADC digitizer) can measure an average time centroid of the arriving charge. From purely atatistical considration we would expect (if we keep $E / p$ constant as we change pressure $p$ and if we assume that the electron cloud is approximately Gaussian in a given timing acceptance window]:

$$
\sigma_{\text {diffurion }}=\frac{1}{\sqrt{(\eta N p n)}} \cdot \frac{\sigma_{L}(1 \text { electron })}{\sqrt{p}},
$$

where $N$ is the total number of charge clusters arriving at the anode (at 1 atm), $p$ is the pressure, $\eta$ is the fraction contributing to particular timing acceptance window, and $n$ is the number of electrons per cluster. The $n$ can be influenced by a similar set of variables as for the leading edge timing, but in addition we can have variables like a choice of the waveform digitizing electronics (speed of the FADC's) or a method of analyzing the data (a particular choice of weighting scheme of the FADC bins. 
Comparing eqs. (2) and (3), one would expect a considerablo improvement in the center-of-gravity timing compared to the leading edge timing. Indeed, great improvements in timing resolution werc expected by the introdnction of the FADC's on the market recently. One can say that the odffatlot term in eq. (1) has been indeed reduced; however, this has been achieved at the expense of increasing the $\sigma_{\text {loninallon }}$ term. This can be fully understood only after we explain the detrilo of the charge collection geometries and we will return to this point later. Here we would only say that, due to the nonisochrony of the charge collection, the fuctuation in ionization statistics will affect the variance significantly and thin will cause the predictions using eq. (3) to be alwayn too optimistic.

\subsection{Monte Carlo Method}

The danger of all Monte Carlo techniques is that they sooner or later become a black box and one loses the feeling of transparency due to an interplay of too many variables. It is not our inteation to review all previous attempts to write such codes. We will just describe our contribution to this problem. Before attempting to write such a program, it is very important to select the variables that contribute significantly to the resolution, as well as to keep in mind the final result (apart from pretty pictures). We have attempted to write such a code [7] with the hope of belng able to predict the resolution for a previously unknown geometry [8] as well as to find some trick in a possible timing technique [9]. The method consists of including threc basic elements of the detection process:

Generate the drift time distribution $i_{\text {drit }}(t)$ by:

(a) creating the primary ionization in clusters (Landau affect) according to Piuz and Lapique [10],

(b) drifting each electron within each cluster independently in a two-dimensional electrostatic field,

(c) using the correct drift velocity in each step,

(d) including the effect of the magnetic field, 
(e) and including the effect of the difusion $\left(\sigma_{L}\right.$ and $\left.\sigma_{x}\right)$.

Generate the tesponse of the avalanche $i_{\text {anlanebe }}(t)$ by:

(a) including the effect of the motion of the positive ion,

(b) and including the effect of the avalanche fuctuations.

Generate the response of the electronics $i_{\text {electronla }}(t)$ by:

(a) using the measured response of the amplifier,

(b) including the effect of zero-pole filters to perform proper shaping of the final pulse,

(c) as well as including the effect of cables and noise.

The final drift pulse is then a convolution of the three terms $i(t)=i_{\text {drift }}(t) \times$ $i_{\text {aralasho }}(t) \times i_{\text {elestrodes }}(t)$. It is important to point out that the method sssumes a full linearity in the process of the waveform formation, i,e, all drifting electrons have equal weight. This can be satisfied only at low gaing. An example of such pulses can be seen in fig. 8 . Once we have created such pulses we can investigate various timing strategies, for instance (a) first electron timing, (b) multiple threshold timing, (c) various strategies with waveform digitizers, etc. As I said, this makes sense only before we build the chamber; once we have data, of course, it is better to use it instead. An example of what appears to be a correct prediction by this program is the conclusion that the $100 \mathrm{MHz}$ digitizer is not fegt enough to improve on the simple first electron leading edge timing in the first few centimetert of drift and in a cell structure like a jet chamber using a fast gag [9]. We will use several other examples of output from our program during the following text.

Rerently there have betn other attempts to study the drift chamber using the Monte Carjo techniques $[11,12]$. For instance, experiment NA34 in CERN [12] used such a program to study the proper shaping of their electronics to obtain an optimum double track separation. None of the previous Monte Carlo programs treated the avalanche entirely correctly. Recently there has been an attempt 
in a correct direction, namely the avalanche is treated three-dimensionally [43]. However, the success of auch simulations will depend on a knowiedge of iaput data for a particular gas operating at very large elertric gradieato. Such simulations might be necessary to understand aystematios of the detection for resolutions below 10-15 $\mu \mathrm{m}$.

\section{Examples of Charge Collection Geometries}

Figure 9 shows typical examples of the charge collecting geometries used in existing protet jyes or physics experiments. Table 1 provides typical results. Ona must admit that most of the results come from the tests rather than the real experiments; however, at the same time one should point out that the serious attempts to reach good resolutions in the vertex chambers are ralatively recent.

None of the charge collecting geometries are truly isochonous as in 6g. 10(a), although there are varlatiuns in the degree of the isochronity between various detectors. In an fdeal isochronous case all electrons from the track sample would reach the anode at the same time and as a result the $\eta$ factor in ers. (2) and (3) would be largest, we would obtain the best multiple hit capability and the center-of-gravity timing would be less sensitive to the finite ionization statistics and the Landu effect. Instead, a more typical charge collection is described in fig. 10(b). However, even in an ideal isochonous case there is one problem. As we aignificantly incline the track with respect to the anode plane we obtain very nonisochonous charge collection, subject to the same problems as in the case of fig. 10(b). There is only one solution to this problem and that is to decrease the sample size up to the point that we still obtain good single track resolution. In the following examples we will see that one can limit the sample size eithar (a) physical]y [11], (b) electrically $[13,14]$, (c) or using soltware [15]. We will now describe typical examples of the charge collecting geometries as uned in existing prototypes. 


\subsection{JET GEOMETRY}

This concept was pioneered by JADE [16] and it is presently concidered by many groups for a posible verter detector. This is primarily because of the simple time-to-distance response, the reasonable multiple hit capability, the low sensitivity of the resolution to the angle of the tracks as well as "clean" electrostetics of the cell. On the negative side of this concept, this cell represents a decreased flexiblity in the choice of an operating point, i.e. selection of the gain, clectric field and the gas (theg have 10 be "masried" together). Aloo, in view of our previous discussion, the charge collection in the cell is far from isochronow, see fig. 11. Figure 11(a) shows how the clutering (Landau) and the ionization fluctuation affects the randomreas in the pulse shapen, a point which will be discussed quantitatively later. The fig. 11(b) shows the effect of the drift distance on the inochronoun repponse, i.e. for track going through the anode plaze one simply runs out of atatistios in the firat arriving charge and this effect is responsible for a worsening of the resolution for distances less than wire spacing (the only remedy for this problem is to fncrease the pressure - see fig. 7). Figure 11(c) shows the charge collection for inclined tracks. Because the bottom of the U-sbapes remain relatively unchanged, the resolution as obtained for instance by a leading edge method ahould remain unchanged, althongh the multiple hit capability will clearly be worse at larger angles.

Ore could ask a question whether we can improve somehow the isochrony of this chamber. Figure 12 indicates that one can do it by a suitable choice of the gas behavior [17]. If we operate "behind" the peak in the drift velocity, the electrons drifting near the potential wirea (where th: field to lower) can pick-up speed and the U-shape response in fig. 11 geta fiatter. This is then manifested in shorter drift time distributions and the 7 -factor in the eqs. (2) and (3) should increase. One can see however that at larger magnetic fields $(B>5 \mathrm{kG})$ this particular methad of focusing will atop working. Clearly, the $90 \% \mathrm{Ar}+10 \% \mathrm{CH}_{4}$ is not the best gas from the platean behavior and the diffusion point of view and 
one would have to try to lind a better mixture. One example of a gas with this behavior is $93 \% \mathrm{Ar}+3 \% \mathrm{CO}_{2}+4 \% \mathrm{CH}_{4}[44]$.

One example of a high resolution applieation of the jet chamber concept [18] can be seen in fig. 13. The teat achieved $\sim 23 \mu \mathrm{m}$ revolution for $1 \mathrm{~mm}$ average drift distance using a "hot" gas (75\% $\left.\mathrm{C}_{3} \mathrm{H}_{3}+25 \% \mathrm{C}_{2} \mathrm{H}_{4}\right)$ at 4 atm and uning the leading edge electronics. Uaing the eq, (2) we would expect $\sigma_{\text {alfunos }} \sim 18 \mathrm{~mm}$ (eee table 6), astuming that only $0.8 \mathrm{~mm}$ of track sample contributed [7] and that we have $\sim 34$ elusters in $1 \mathrm{~cm}$ of treck and $\sim 3$ electrons per elupter in this gos. The chember had $2.5 \mathrm{~mm}$ wire apaeing with the potential wire fully collecting charge and with a simple "owitchyard" multjple hit electronles they obtained $\sim 1 \mathrm{~mm}$ double track separation. One bad feature of this particular arrangement is a ripple in the electrostatic field around the boundaries of the cell. This chamber can be regarded as a predecessor of similar but somewhat larger chambers built for the NA27 experiment at CERN, which in uning them for the physico running presently.

A second example is the micro-jet chamber concept [19] seen in 6g. 14. The idea here is to further decreare the anode wire apacing $(1 \mathrm{~mm})$ to improve the double track separation. In this case it was necessary to use a contintous cathode to limit the field emission problems (if the wires for the cathode wera used instead). The continuous cathode should increase the chamber lifetime an well as to improve the uniformity of the electrostatic field near boundaries. Finally, we use very thin anode wires $(7.8 \mu \mathrm{m}$ diameter) which can easily drive the amplifer [20] into a slowing rate limited mode reducing the alewing corrections to a minimum. The use of thin wire linits the overalj length of the chamber to $\sim$ 10-15 cm. We would like to mention that these wired proved to be mach more resistant against the breakage then one would initially expect. The chamber obtained $22 \mu \mathrm{m}$ resolution for $2 \mathrm{~mm}$ average drift distance in a "hot" gas (90\% $\mathrm{Ar}+10 \% \mathrm{C}_{1} \mathrm{H}_{10}$ ) at 6.1 atm with a simple leading edge timing. As one can wee from fig. 6, its slectric field of $1.5-2.0 \mathrm{kV} / \mathrm{cm}$ atm was about an optimum from the longitudinal diffusion point of view. We cannot use the eq. (2) in this 
particular case because we bave not kept $E / p$ constant as we changed the pressure p. We use instead $\sigma_{\text {difurion }} \sim 0.91 / \sqrt{\ln (0.6 \times \overline{6.1} \times 3 . \overline{0})} \times 130 \mathrm{kzI} / \sqrt{\mathrm{cm}} \times$ $\sqrt{((14.6 \mathrm{kV} / \mathrm{cm}) / 6.1 \mathrm{~atm})^{13} \times 0.2 \mathrm{~cm} /(14.6 \mathrm{kV} / \mathrm{cm})} \sim 16 \mu \mathrm{m}$, nasuming that only $\sim 0.2 \mathrm{~mm}$ of track semple contributes to the leading edge timing [9] and that wo have $\sim 30$ clustess in $1 \mathrm{~cm}$ of track and $\sim 3$ electrons per clunter in this ges, wid the loogitudinel difirsion sosmalized for $1 \mathrm{ki} / \mathrm{cm}, 1 \mathrm{~atm}$ and $1 \mathrm{~cm}$ drift $130 \mu \mathrm{m} / \sqrt{\mathrm{cm}}$. Mearoring the average shapes of the drift pulses in the $a^{+}$beam one would concludn that the donble track separation is about $600 \mu \mathrm{m}$ uning a alople switehyard weetronirs, and that this could be improved further waing $\geq 200 \mathrm{MHz}$ dlgitizcr [21]. The electronics resolution obtained in the test was about only 61 pace and a $N_{2}$ laser was used to ture souse of the operating polnts [22]. At higher rates applieations one would have to reduce the gain and this would requlre taking care of olewing either electronically using the constant fraction diseriminator [23] or in the sothere if double threshold electronics would be uaed [9].

A third exanple of thlu atructure is the SLD \#1 prototype which has been terted at SLAC [24]. With a cool gan of $92 \% \mathrm{CO}_{2}+8 \% \mathrm{C}_{4} \mathrm{H}_{10}$ at 1 atm the chumbar obtained lntaratiag rarult as sen in fig. 15. The chamber uged the leading adge electronies. Uting our almple eq. (2) and assuming that $\sim 1 \mathrm{~mm}$ of the track ample contribater one expects in $1 \mathrm{~cm}$ drift $\sigma_{\text {diffurion }} \sim 49 \mu \mathrm{m}$ (sue table 5).

Finally, we want to mantion a development of the UA1 vertex detector. The $80 \mathrm{~cm}$ long Jet ehember with $1.59 \mathrm{~mm}$ wire spacing achieved $\sim 40-50 \mu \mathrm{m}$ resolution for $\sim 0.6 \mathrm{~cm}$ drift in $50 \% \mathrm{Ar}+50 \% \mathrm{C}_{2} \mathrm{H}_{6}$ gas at 3 atm [45]. Again, we get - good agreement with the eq. (2), if we use $0.6 \mathrm{~mm}$ as an effective sample size (see table 5). 


\subsection{Gymorigal Geometay}

Examples of such geometry are the vertex detectors for the Mark II at SLAC [25], the ARGUS at DORIS [26] and the Aachen Univeraity tat [16]. The former is already producing physics, the aecond Is about to atart. The advantage of thit concept is that it is a aimple geometry requiting telatively amall number of wires. On the negative side, the cell has considerablo adge offecta - cee ff. 16: It is very nonisochronous and has a nontriform electric fleld throughout the cell. Nevertheless, the beam test with the ARGUS vartex datector indleates resolutions in the range of $40-80 \mu m$ using gages at 1.5-2.0 atw. Tho Aachan University test achleved $\sim 30 \mu \mathrm{m}$ resolation for $\sim 8 \mathrm{~mm}$ drlft distance ung $80 \% \mathrm{CO}_{2}+20 \% \mathrm{C}_{4} \mathrm{H}_{10}$ gas at 1 atm [46]. The rosults can be rean in for. 32 and we will discuss them care in chapter 5 . We would also like to mentlon the vertex chamber prototype utilizing closaly packed $7 \mathrm{~mm}$ diamator aluminized. mylar tubes which was recently tested by the MAC exporiment at SLAC [DI]. With the hot standard gases operating at 4 atm they have achloved resolation in the rangu of $30 \mathrm{fm}$. The obvious advantage of this aystom is its simplicity.

\subsection{SAMPLE RESTRICTLNG GEOMOTRY}

Figure 17 ghows an example of a geometry whare tho accopted track anmple in restricted physically [11]. As we discussed earlier thls ahould Improva the doublo track separation as well ag reduce the sersitivity of the resolution and double track aeparation to angles of the track with respect to the anode plere. We can see that by using a cool gas at $1 \mathrm{~atm}$, the teat achieved a recolution of about! $30 \mu \mathrm{m}$ for $1 \mathrm{~cm}$ of drift. Usirg the eq. (2) and asauming 29 electron in $0.8 \mathrm{~mm}$ of accepted sample at $4 \mathrm{~atm}$ we would expect odtretos $\sim 17 \mathrm{pm}$ (bea table 5 ) for the first electron leading edge timing. As one can sea trom fo. 17(d) a double track resolution of about $100-300 \mu \mathrm{m}$ achieved. The atthos hare shown that a further incresse in pressure did not achieve a further improroment in the resolution, presumably due to the aftaciment problem in $\mathrm{CO}_{2}$ mixtures. 5 gain 
17(e) indicates their proposal of how to implement one version of a sentrictive Beometry in practice.

\subsection{Spectal Focusing Geometry}

We have two examples where an attempt is made to focus the flow of drifting electrons to improve the isochrony of the charge collection. The fird example can be seen in fig. 18(a) [13]. This geometry was chosen for a prototype test by the NA34 eperiment in CERN. The ides is to use the channeling wires (c) to contrcl the accepted track tample size from $\sim 3.5 \mathrm{~mm}$ to $\sim 7 \mathrm{~mm}$. In this way they could study the sensitivity of the single track resolution as weil as the double track separation to the sample size length without the necessary of building different prototypes. In sddition the structure separates left-right collection. Figare 18(b) indieates the lines of equal arrival times to the anode for voltages corresponding to the smallest ( $3.5 \mathrm{~mm}$ long) accepted sample length. One can see that the structure is not completely isochronous, in fact only $\sim 2 \mathrm{~mm}$ of the track length contributes to the first charge arrival. Figure 19 (c) shows the single track resolution in the "cool" gas of $90 \% \mathrm{CO}_{2}+10 \% \mathrm{C}_{4} \mathrm{H}_{10}$ at $1 \mathrm{~atm}$. Again, if we use the eq. (2) and assume $\sim 2 \mathrm{~mm}$ of the track sample contribating to the definition of the first electron timing we get $\sigma_{\text {diffusion }} \sim 42 \mu \mathrm{m}$ (see table 5) for $1 \mathrm{col}$ of drift, i.e. rather close to the measured zesults. They observed that by varying the track sample length one does not vary the single track resolution (i.e. the first electron timing is derived from the first $\sim 1.5 \mathrm{~mm}$ of the track length), but one can affect the double track length separation (the overall drift time distribution length gets larger for larger accepted track sample). They studied the double track separation using the $\mathrm{N}_{2}$-laser and they found $\sim \mathrm{BO} \%$ efficiency to fod the second track if it is $\sim 600 \mu \mathrm{m}$ apart frosa the first track. One ahould also mention that they have developed a drif program [12] to carefully tune shaping constants of the electronics for a particular mixture with the $\mathrm{CO}_{2}$ gas. Fivally, this collaboration has built the charge restricting strutture [38] similar in concept to that indicated in fig. 17(e), but with a $2 \mathrm{~mm}$ restricting gap. The aingle track 
reablution results are thown in fig. $18(\mathrm{c})$ and are esentially in agreament with the results of the focusing geometry of fig. 18(a), although, one would expect that the rentricting geometry should improve the double track separation.

The second example in fig. 19 comes from the SLD propoal at SLAC and it was atudied both experimentally [50] and theoretically using the Monte Carlo program [8]. The collecting geometry resembles the jet focusing geometrs, however the potential wires are dropped. One wonld apect that this structure will enhance somewhat the $\eta$ factor in the eq- (2) duse to an increase in the effective anmple vire compared to a simple jet geometry. Indeed, comparing fig- 19(b) and fig. 15, we can see a small improvement of the resolution in case of the focusing geometry. Table 5 compares the experimental results with the eq. (2). Solid curve of fig. 19(b) showr more sophinticated Monte Carlo prediction [8]. The real advantage of the focusing geometry over a simple jet geometry is in an improvement of the multiple hit capability-

Figure 35(d) ohowe one of the prototypes of the Mark II gronp [47[. The $30 \mathrm{~cm}$ long test chamber operating with $92 \% \mathrm{CO}_{2}+8 \% \mathrm{C}_{4} \mathrm{H}_{10}$ gas at $3 \mathrm{~atm}$ achieved $\sim 35 \mu$ m regolution for $1 \mathrm{~cm}$ drift.

\subsection{TRME EXPANSION GEOMETRY (TEC)}

Thic concept was originally proposed by Walenta [27] and it is being presently puraued by the LEP3 collaboration [14]. Figure 20 shows the present arrangement during the test. The original concept of pick-up wires to determine the angles of the tracks has been abandoned. A pair of focusing wires are tued which by proper binsing control the size of the accepted sample size (typically $\sim 2 \mathrm{~mm}$ of track length). No attempt to measure individual clusters is made presently, one determines the centroid of the average charge by the IOD MHz FADC electronics. The tail due to the positive ion response is eliminated by a proper ahaping electronics [20] to improve the multiple track capability. The TEC concept when implemented with the mesh electrodes (test used a $250 \mu \mathrm{m}$ mesh) represents the 
most ideal geometry becutut the goin and the drtf regions are separated and one has a total freedom to choose the chambers parnmeters. However, the mesh solution is dificult to bmplament in pretice for hrot chambeta and the LEP3 groop bas decided wo test a wite grid indead (1.2 $\mathrm{mm}$ wire spating). The prenent test resolution results with a mech oolntion and the coof gas $80 \% \mathrm{CO}_{2}+20 \%$ $\mathrm{C}_{4} \mathrm{H}_{10}$ can be seen in fig. 29. We will diccus them in detail in the lant chapter. The measured 3o donble track esparation b about $\leq 300$ pm for omall angle tracks $\left(-0.8^{\circ}\right)$ at 2 otm

We should mention that the men colution of this concept was tried also at SLAC by F. VIle [29]. The aignifleanee of this teat is the firt use of law diffusion dimethyl ether gas. This test has been recently repeated $[48]$ and fig. 30 indicates the resultu obtained with the laading edre timlng.

\subsection{RADUL DRTT CHAMEER GEOMETRY (RDC)}

Recently a novel method of rertex reconutruction has been proposed by D. Nygren and J. Euth [49]. The datector la bead on a slow ratial drift in dimethyl ether gas. Fipare 31 thow a basic peomatry of the charge collection. The reconstruction of trach of baced on the concept that every paint in the sensitive volume is mapped by the electric fleld to a corresponding position on the aurface of the enode wire. This poattion on the mode wite can be defined by an

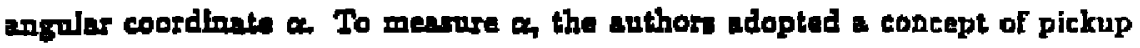
wires origtrully proposed by Walente [27]. The absence of argon, traditionally a mijor component in the drift chamber gen mbtwre, ellminates a strong pource of UV photond which ean broaden the aralanche growh. Therefore, the dimethyl ether inproves the revolution in a-angular coordinate. One should point out that the radial drif $\left(\theta \sim 90^{\circ}\right)$ allows to messure $a(\theta)$ on afl drifting ionization with a better accuracy compared w the originally propased concept where $0 \sim \sigma^{\circ}$ [27]. The most siduilicant feature of this concagt is a utiliation of all created jontration for the foll tiring information. The predicted resolution should follow of (3) with $\eta=1$, le. the technique should improve the resolution with 
a (pressure) ${ }^{-1}$ dependence Another edvantege of this concept ts an abeance af the grid structure which is a mechanieal couplifation. On negattre alde, the expected multiple hit capability is mose compured to what one cen achiene in

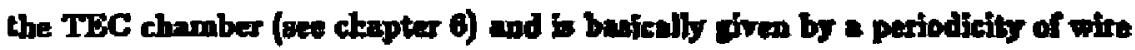
etructure, i.e of the order of millimetart.

\section{Systematic Effects}

It would be unfeir not to discuss the most sfonlficant gratematle effets which will influence the overalt resolation obtained over mang months of the cunning needed in a typical physles run. In the previous chapters we have coen very impressive renulta obtalned with the "cool" cases. The quention is now if the advantager of the "cool" gas ovez the "hob" gan in torma of the difrrion and the lower demand on the apaed of electronice will not be ofiget by the dluadvataga due to larger sengitivity to systewatic effects malnly because the "cool" pases do not operate on the platebu of the drift velocity eurve.

There are basically three types of ayatematic effocts. The firat one is hopt fully congtant in time, examples are nontunform electrontatic field around the cell boundaries, errors In electroatatle dakiection, arrors in mechaniea, fill to fll variations in a gas composition, ote. Thead errors could be calibrated to some extent for instance by the laser. The second type of oyatematic error is changing in time in a not gecessarily controlled way, examples are nonuniform temperature throughout the volume of the ehamber, etc. The thind type of systamatic arrot has to do with details of the sigual creation and propagation on the wits and the way the electronics handles the puteen.

Table 2 aummarizes the senstivity of the opatial enor to an error of 1/1000 in the drift velocity, time, olectric tledd and dearits tor two eramples, and wing - "cool gas (IYC chamber) and the second uslus thot" gat and operating an a platean (JET clumber). We see that exors in the and velocity afiect both concepts approximately equally, however the bendit of aparting an the platen 
of the drift selocity is seen in the senuitivity to erron in the electric field $E$ and the gas density $N$. This is because in the "cool" gas concept we have $\Delta v / v=\Delta E / E$ and $\Delta v / v=\Delta N / N$, and in the "hot gas case we get $\Delta v / v \sim 0.5[\Delta E / E)^{2}[20]-$ see fig. 21 and $\Delta v / v \simeq O(N)$ (sensitivity goes through the $E / p$ dependence of the drift velocity $v)$. We conclude that the "plateat" operation will protect us much bet.es againat drifts in voltage, nonuniformities in the electric field, space charge effecta as well as the temperature drifts [30]. The temperature sensitivity can be seen in fig. 22. On the other hand the Jlow gases will lower a demand on the electronics performance (1/1000 error in time requires the electronics resolution of about 2 us in the "cool" gas and about 200 prec in the cane of the "hot" gar).

We would like to be more specific abont the space charge effects. Let's assume we have a Eruall JET and TEC chambers with $1 \mathrm{~cm}$ drift and $1 \mathrm{~m}$ long wires. In present $e^{+} e^{-}$storege rings the typical eurrent at high luminosities can be as high ag 200 nanoamperes per wire. We would like to ask a question what will be the change in the drift electric field $E$ in the presence of positive ions lesking into the drift rolume from the avalanches on the anodes. $A$ simple minded integration of the Poisson equation reveals that the change of the electric field compared to an original setting will follow an equation $\Delta E=p^{+}(X-d / 2) / \epsilon_{0}$, where $p^{+}$is a density of the positive ions, $X$ is a position in the anode-cathode gap and $d$ is the length of the anode-cathode gap $(1 \mathrm{~cm})$. The maximum change is then $|\Delta E| \leq p^{+} d / 2 \varepsilon_{0}$. The density of positive jons $\rho^{+}=E N T^{+} c / V$, where $\epsilon$ is the fraction of positive ions leaking into the drift volume, $N$ is the production rate of positive ions (200 nanoamperes), $T^{+}$is total positive ion drift time and $V$ is volume (wire length $\times$ sample size $x d$ ). Table 3 summaries regults from three examples. One can see that to lower the drift velocity through lowering the electric field is dangerous because we lower the removal rate of the positive fons. Also, if $\epsilon$ would be significantly increased (bay $\epsilon \sim 0.5$ ) the time expansion concept would become sensitive to the space charge effects. In this context we would like to point out that the physical restriction of the saraple size should help to reduce 6 . As we see in table 3 the plateau operation of the "hot" gasia 
protects wa very well againat the opace charge effects (dve to the tependence $\left.\Delta v / v \sim 0.6(\Delta E / E)^{2}\right)$.

As far w the third syatematic error is concerned, we would like to point out that the additional demand on a ratiple use of such device would pobably worsen its resolution. Long wires, improper termination or stereo layers will bring additional corrections to deal with. Registive wires in the case of charge division will increase the time slowing corrections. Also the uncompensated crosstalk in combination with the ataggering will affect the rise time. However, these problems are too specific to particular examples and we will not discuss them further.

\section{Leading Edge Versus Genter of Gravity Timing}

First of all, let's agsume that we are dealing with high precision drift chembers with maximum drift length of about $2-3 \mathrm{~cm}$. Secondly, the nature of this problem is very much geometry, pressure, gas and operating point dependent, and therefore we will consider the specific axamples where the pulse shaping data exists, namely the JET chamber of OPAL geometry [32], the TEC chamber [14] of the LEP3 experiment, and the Aachen University test [46].

We have made a epecific prediction using the previously mentioned Monte Carlo program [9] that in the jet geometry operating with a fast gas, a $100 \mathrm{MHz}$ digitizer is not fast enough to improve on the first electron timing (because of the ionization fluctuation effect). How does the gituation look one year later when we have the first experimentsl results?

We have ween several experimental examples (table 5 provides an overall strmmary) in the previous chepters where eq. (2) provides rather close approximation to experimentally obtained results with the leading edge timing (even though most practical tests do not trigges on the first electron). This means that for the leading edge timing the diffusion dominates the resolution at $\sim 1 \mathrm{~cm}$ of drift distance and the ionization fuctuation effect represents a smaller contribution. 
Bow is it in the case of the center of gravity timing? Let's first discuss the example of a jet chamber like OPAl, which operates with the "hot" fast gas $3 \%$ $\mathrm{C}_{4} \mathrm{H}_{10}+87.3 \% \mathrm{Ar}+9.7 \% \mathrm{CH}_{4} \sim \mathrm{JADE}$ gas at 4 atm. The typical nonisochrony in this structure ( $5 \mathrm{~mm}$ wire to wire spacing) is shown in fig. 23. We can see that the diffusion is too small to smear this noxisochrony and at the same time the $100 \mathrm{MHz}$ clock of FADC is too slow to provide several samples through a 2-3 mm "Lsochronous" central part of the sample. In fact for any number $(\geq 2)$ of 10 ns bins we will be sensitive to the fluctuation in ionization statistics, which will shift the timing castroid significantly. One would expect that we reduce the sensitivity to this effect (and therefore improve the resolution) as we reduce the number of bins included in the timing z'gorithm. This is exactly observed in the data. Figure 24 indicstes a time pulse reference method used in the FADC timing of the test with the OPAL full length prototype [15]. Table 4 shows the obtained resolution as a function of the method used. The best result is obtained If we we only two FADC bins for the reference timing. The measured 3-wire rasoiution is about $100 \mu \mathrm{m}$ for $1 \mathrm{~cm}$ drift with the JADE gas at 4 atm. For comparison, if we use the eq. (2) pre would expect for the first electron timing Odifulsa $\sim 0.91 \sqrt{\ln (4 \times 6 \times 3.0)} \times 250 \mu \mathrm{mm} \times 1 / \sqrt{4} \sim 55 \mathrm{\mu m}$ for $1 \mathrm{~cm}$ drift, and the eq. (3) for the center of gravity timing would give (a 20 als window eccoptance cut) $\sigma_{\text {difiniso }} \sim 1 / \sqrt{(4 \times 15 \times 3)} \times 250 \mu \mathrm{m} \times 1 / \sqrt{4}=10 \mu \mathrm{m}$. This mears that the experimental result is domfnated by the ionization fluctuation effect and is worse than what we would expect from the leading edge timingThe second example comes from the Heidelberg test chamber [31], which has the seme wire geometry but longer drift length. The results are shown in fig. 25 for various operating conditions. The fit to data is made using a function $\sigma^{2}=$ $\sigma_{f}+\delta \cdot X$, whare $\sigma_{0}$ contains mainly a contribution from the electronics and the jonfzation fuctuation effect. The fit indicates $\sigma_{0} \sim 70-100 \mu$ m at 4 atm and 135-160 $\mu \mathrm{m}$ at $2 \mathrm{~atm}$ depanding on operating condition. Since the error in electronic contributes only 20-30 $\mu \mathrm{m}$, one would again conclude that $\sigma_{0}$ is dominated by the ionization fluctuation effect (assuming that all other syutematic 
contributions are neglfgible). It is interesting to predict the frst electron leading edge capability for the best FADC data at 1 atm. Uaing Gg. 26 we expect of $155 \mu \mathrm{m}$ for $1 \mathrm{~cm}$ of drift at $E / p \sim 0.47$. Using the eq. (2) we expect $\sigma_{\text {diffuriog }} \sim$ $0.91 / \sqrt{\ln (4 \times 6 \times 3)} \times 165 \mu \mathrm{m} / \sqrt{4} \sim 34 \mu \mathrm{m}$ for $1 \mathrm{~cm}$ drift, assuming that $\sim 2 \mathrm{~mm}$ of track sample contribut to to the leading edge timing in this particular geomatry. It is interesting to point out that the bost resolution is obtained at largest $\boldsymbol{E}$. This is because of an improvement of the longitudinal diffugion as we incresse $E$ (see fic. 26) and the as focuging effect mentioned earlier (yce fig. 12). We have not yet mentioned so far another important variable and that is the gain on the wire. Both previous examples $[15,31]$ operated at relatively lower gain $\left(<5 \times 10^{4}\right)$, because of the $d E / d x$ application. In typical vertex chambers the gain is larger and one expects that some portion of the later arriving charge will be affected by the saturation effect. This will effectively tend to reduce the sample size for tracks reasonably perpendicular to the wires $\left(\theta \sim 0^{\circ}\right)$, and one expects that the pulge waveform is more derived from the very early charge and therefore the centroid timing would approach the leading edge timing. If this is true one would expect some a-dependence in the centroid timing resolution. Exangle of udih application is the JADE experiment vertex deteitor [42]. They bave ehicied $\sim 100 \mu \mathrm{m}$ resolution for $1 \mathrm{~cm}$ drift using the first two FADC timing bins in $50 \%$ $\mathrm{Ar}+50 \% \mathrm{C}_{2} \mathrm{H}_{6}$ gas at 1 atm. This is compatible with the expectation besed on the eq. ( 2 ) for the first electron timing since the $\sigma_{L}(1$ electron) $\sim 200 \mu \mathrm{m}$ in this particular gas at $1 \mathrm{kV} / \mathrm{cm}, 1 \mathrm{~cm}$ drift and $1 \mathrm{~atm}$. We gec that the centrold timing will appronch at best the leading edge timing at high gains in the frigt gar.

Ons can ask the question under what condition oe would improve the first electron timing in the jet chamber operating with the fast gas. Figure 27 show the various simulated resolution results if we assume infinitely fast electronie: capable of recording the arrival time of every electron [9]. We can sea thist the certer of gravity timing improves the first electron resolution only If we sversge over electrons in the near-isochronous central part of the sample (see fg. 23). A: we average ovar larger parts of the sa mple (wider time window cut) the center of 
gravity is disturbed by the fuctustions in ionisation atatiotics coupled with the nonisochrony of the charge collection. As we increase the pressure the diffusion gets smaller and the apparent isochmnou part is eren amaller requiring amaller timing cut. If we had $\sim 1$ GHs digitirar we would have a vomewhat aimilar situation as in the TEC chamber we will dipcuss next, i.e. we would not detect every electron but instead have several samples through the avaragecharge in the isochronous part of the f.g. 23. With approximate cuts one could isolate this part of the signal and one would still expect an improvement over the firat electron. timing. One can express it differently, a $200 \mathrm{MA}$ : digitizer would provide better resolution than $\sim 100 \mathrm{MH}$ one, because we can further reduce the sample size through the timing cut.

How is it now in the TEC chamber [14]? Figure 28[a] shows details of the electroatatios of the charge collection. Figure 2B(b) describes the approximately isochronous behevior in this chamber. We can see that it is not isochronous, but the nonisochrony affects only a 8mall part of the track asmple reducing the probability to have the innization there. More important, the diffurion smeart the charge to the point that we can consider that most of the track sample is isochronous. Finally, the speed of the $100 \mathrm{MHz}$ digitizer is a good match to the low drift velocity providing 3-5 samples through the isochronous part of the sample. We would then expect that the center of gravity has a better chance to improve the leading edge timing. Figure 29(b) indicates a comparison of the leading edge timing with the center of gravity technique. Unfortunately this measurement is not yet conclusive evidence because the threshold for the leading edge timing was set apparently rather high ( $\sim 6$ electrons) [33]. Fur the first electron timing we would expect $\sigma_{\text {difinion }} \sim 0.01 / \sqrt{\ln (2 \times 6 \times 3.0)} \times$ $100 \mu \mathrm{m} / \sqrt{2} \sim 34 \mu \mathrm{m}$ for $1 \mathrm{~cm}$ of drift at $2 \mathrm{~atm}$. On the other hand, the diffusion contribution using the center of gravity timing [eq. (3)] is $\sigma_{\text {ditrution }} \sim$ $1 / \sqrt{2 \times 6 \times 3)} \times 100 \mu \mathrm{m} / \sqrt{2} \sim 11 \mu \mathrm{m}$ for $1 \mathrm{~cm}$ of drift. Since the electronics gives a small contribution [33] we would conclude that other systematic effects including the finite ionization statistics, the flnite speed of th: digitizer, the 
diffuion near the anode wire, etc. still contributed the large contribution to their meanured results. This is also visible if we tuse their fit to the data $\sigma^{2}=$ $\sigma_{0}^{2}+\delta \cdot X$ where $\sigma_{0}=19 \mu \mathrm{m}$. Because $\sigma_{0}$ is so tmall it is harder to determine the dominating term in this particular case. Anyway, our concluaion in that both timing techniques will be approximately equivalent for $\sim 1 \mathrm{~cm}$ drift distance. The real ber zit of the center of gravity timing is expected through far larger drift distancos $(>2-3 \mathrm{~cm}$ ) where the diffusion will cause the leading edge resolution to be worse.

Final example comes from the Aachen University teat [46], where the cylindrical cell was tested with the cool gas $80 \% \mathrm{CO}_{2}+20 \% \mathrm{C}_{4} \mathrm{H}_{10}$ and using both the leading edge and $100 \mathrm{MHz}$ flash $\mathrm{ADC}$ electronics. Figure 32 thows the results. One can that the leading edge timing is aignificantly better for small distances from the anode wire and both methods yields similar rasults forther away from the wire. The explanation is rather simple. For a cylindrical cell where the field $E$ is approximately proportional to $1 / r$, and for a cool gae like $\mathrm{CO}_{2}$ with vdrin proportional to $E$, one expects that the drift velocity is rapidly changing with the distance from the arode wire - see fig. 32(a). Far from the wire, the charge collection is more isochronous compared to smail impact parameters, where the velocity begins to be too large. The $100 \mathrm{MHz}$ clock, similarly like in our first example, is too slow for emall impact parameters and the ionization fluctuations begin to dominate the FADC timing.

\section{The "Ultimate" Deeign?}

All arguments in this chapter are based on the computer simulation of the problem. As we gajd earlier the mesh represants the ideal electrostatic boundary in the TEC chamber. However, it is difficult to iraplement in practice for larger chamber designs. Figure 33 shovis several alternatives to the mesh solution as simulated by the author. The basic wire geometry and the voltages were kept the same as in fig. 28(a), however, the mesh was replaced either with a foil 
or a grid of wires. The simulation was performed for $92 \% \mathrm{CO}_{3}+8 \% \mathrm{C}_{4} \mathrm{H}_{10}$, $E \sim 1.1 \mathrm{kV} / \mathrm{cm}$, pressure $p=2$ atm and the difusion parametrization according to fig. 2. For clarity of the picture, the clustering was switched off and the amount of ionizaiion was artificially increased. The question is then what kind of effect these geometrical solutions have on the isochrony of the charge collection. Figure 33(a) shows a case where the foils are separated by a $1 \mathrm{~mm}$ gap. One can see that in this case there is a nonisochrony due to a ripple in the electrostatic field caused by the $1 \mathrm{~mm}$ gap. In fig. 33(b) we tried to remove this problem by placing one wire in the middle of the gap. In fig. 33(c) we used a $1 \mathrm{~mm}$ grid. In this case one obtains the worst nonisochronots candition, which will tend to create a tail in the drift pulses. The case of $\mathrm{fg} .33(\mathrm{~b})$ is clearly the best. For a drift distance larger than $1 \mathrm{~cm}$ the diffusion makes this geometry truly isochronous. According to our aimulation one expects a $3 \sigma$ double track separation of about 80-150 $\mu \mathrm{m}$ for $\sim 1 \mathrm{~cm}$ drift. If we incline the track by $10^{\circ}$ this quantity will double. Figure 34 shows a version of what one could consider an "ultimate" design of the vertex chamber. As we can see it is a combination of the TEC concept, and the charge restricting and the charge focusing geometry.

As we said the diffusion will smear the nonisochrony after a certain drift distance. This distance is pressure dependent. For instance, at 2 atm we will not see much difference jn width of the drift time distributions between the designs on fig. 33 after a drift distance of about $2-3 \mathrm{~cm}$. Figure 35 shows the drift time distributions at atm for various designs and several drift distances. Figure 36 shows the same but for tracks inclined by $10^{\circ}$ with respect to the anode plane. One can see that at this pressure and a drift distance of $22 \mathrm{~mm}$, the design (a) has FWHM of the drift time distribution typically 20-30\% amaller compared to the design (d) of fig. 35 [6. 35(a) $\equiv$ fig. 33(b)]. This will have a consequence on the multiple hit capability. How does it affect the resolution? We have performed the resolution study on these two designs (a) and (d) of fig. 35, with infinitely fast electronics as well as with realistic pulses generated with a realistic primary ionixation, and convoluting the drift time distribution with a responge of an 
amplifier and one zero pole filter. The results of this study are summarized in table 6. We conclude that the centroid timing with the infinitely fast electronics capable of detecting each electron separately follows approximately the eq. (3), however, the centroid timing with the realistic pulses and a $100 \mathrm{MHz}$ digitizer is worse, and it is about equivalent to the frst electron timing for $12 \mathrm{~mm}$ drift distance. This is even true for the ideal isochronous design of fig. 33(b). We interpret this as an indication that even for the slow gas the $100 \mathrm{MHz}$ digitizer is not fast enough to provide a true representation of the pulse shape and therefore we do not achieve the ultimate resolution as given by eq. (3). This points to a need to increase the speed of the digitizers. If one would achieve the resolution as predicted by eq. (3), we would directly compete with the ablid state devices! There is certainly enough primary jonization produced at 4 atm to expect this. The question ls what the electronics does with it. One will have to find a correct compromise between the amplifler speed and the digitization speed. Application for this? - The innermost layers of the vertex chamber.

\section{Conclusion}

(a) For applications where an excellent resolution, multiple track resolution, insensitivity to angles and insensitivity to the space charge effects is required, I would consider the TEC chamber with the restricting curtaing. The challenge here is to come up with the best possible design of the reobricting curtains. It can be operated either with the "cool" or "hot" gases depending on the environment, and evtn with simple leading edge timing and multiple hit "switchyard" electronics one can achieve very good results. For applicatione where the multiple track separation is not important the simple jet chamber or the tube design will perform well. The rilial drift chambar is atill in a prototyping stage.

(b) More work should and will be done on an improvement of the charge collecthon focusing techniques, ejther through a vuitable choice of a gas or using 
electrical fields (or both). Here the aim in mainly to improve the doubla hit capability.

(c) If the chotice it a "cool" gan, much moce wark should go to studive of the syutematic effecta.

(d) For the fast gases, lower eains and drift distanew less than 1-2 em, a oimple lending edge timing will provide better reolution than existing $100 \mathrm{MAB}$ wareform digltizars. At bigh gains the centrold timing will approceh the leading edge timing. In the cses of slow gaves and depending on exnet charge collection geometry, the $100 \mathrm{MIII}$ digltiner will provide comparable results to the leading edige technigne for amall drift dintancea. By the leading edge we mean the $\sim 1$ electrm threahold timing. Curtinly one should not expect a dratic improvement wexording to eq. (3), whlos wo create a truly isochronous geometry, find woms tricl to correethy roprodece the drift pulses in a process of digitization and learn rore about dotalls of remaining systemstic errors.

(b) For larger distances $(2-3 \mathrm{~cm})$ the pulse ahapa tiring will definitely bo better than the leading edge timing becense the cumittvity to diffinson is reducod.

(i) To achieveresolution better than 40 pm for 1 em drift, one has to presurine the gas to 24 atm. To improve the resolution through an Iuprovement of the collection optics is a much wlower way to gain.

\section{ACKNOWLEDGEMENTS}

We would like to thank Professor J. Heintse for discussions of evered topled in this peper. We aluo appreciate comments about thin aubject by Dr. G. Viartal and Professor A. Wagner. We also thask J. Fehimann for running the proterata to predict the diffusion parametece for several gas mirtures (4). 


\section{REFERENCES}

[1] G. Churpak and F. Baull, CERAN-EP/84-35, submitted to Annual Review: of Nuclear Eclences.

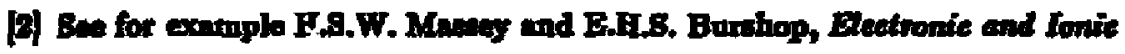
Inpact Phenomene, Oxford, 1998.

(B) B. Schmidts. Heldalberg diploms thesis, 1980.

[4] J. Jahlmann, J.A. Paradino and G. Viertel, "WIRCEA" Frogram Packege to Simulate Drift Chambers, ETH Zürich, 1983.

[b] W. Prr, J. Holntse, K.H. Hellembrand and A.H. Walenta, Nucl Inxtrum. Mathoda 154 (1978) 175-181.

[B] E. Cramer, Mothematieal Methods of Statistics, Princeton Univenits Prea, 1066, p. 374.

[7] J. Va'vee and L. Roberts, DRIFT Program, SLAC, 1982.

[8] C. Preicott, SLD Group, Uaing a program of ref. [7].

[O] J. Va'vrs, 8LAC-PUB-3131, presented at the 2ad Pien Meeting on Advanced Detectorn, Custlgllone, 1983; and Kucl. Instrum. Methods 225 (1084) 44.

[20| F. Laplque and F. Pjos, Nuel. Inatrum. Methods 175 (1980) 297.

[11] B. Bobkov et ah, CbRR-EP/os-81.

[12] D. Bettoni and A. Rudge, NA34 Internei Note \#48.

[13] D. Bettoni et al, NA34 Experiment Note, presented at Internationnl Conference on High Eaergy Phyaics, Brighton, 1983.

[14] Aachen-Siegen-Zürich Vertex Chamber Group, preaentod at S. Miniato Meeting on Future High Energy Machines, Florence, Italy. 2384.

[15] H. Jurckhart, J. Ve'vra, K. Zankel, U. Dudxiak, D. Friedrich, O. Schaile, P. Irannert and P. Igo-Kemente, to be published. 
[16] H. Drumm et al., Nucl. Inatrum. Methods 176 (1880) 338-944.

[1T] J. Ve'vre and L. Roberts, BLC Note "31, SLAC, 1982.

[18] B.R. Belan, W. Blum, 2. Hajdnt and T.W.I. Snnford, Nucl Instrum. Methods 192 (1982) 21\%-2:1.

[19] J. V'vra, Nucl. Inatrum. Methoda 217 (1983) 322-326.

[20] R.A. Boie, A.T. Hrisoho and P. Rehak, Nocl. Instrum, Mothod 192 (1982) 365-374.

[21] SLD Design Report, BLAC, 1994

[22] J. Ve'vra, SLAC-PUB-2984 (1985).

[23] OPAL Verter Chambar (Rutherford Lab. Blectronica).

[24] STD Central Detestor Gropp, presiented by B. Imeh at 8. Minlato Mecting on Puture Bligh Bnerwy Machines, Florence, Italy, 1984.

[25] J. Jaros, proceedings of the Interantional Conference on Instruments for Colliding Beam Phyle, SLAC-250, 1982.

[28] ARGUS Vertex Datector Group, presented at S. Miniato Meating on Future Fing Bnergs Machine, Florence, Itab, 1904.

|27| A.H. Walenta, procedings of the International Comfarence on findruments for Colliding Beam Phyio, stac-260, 1992.

[28] P. Villa, Kucl. Inctrum. Method 217 (1083) $273-278$.

[28) K.F. Fellenbrand, Fidelbere diplome thesis, 1800.

[30] G. Bchultz and J, Grenar, Nucl. Instrum. Methodu 151 (1078) 413.

[31] I. Smolik, Heidolbarg diplome theala, 1984; presented by J. Heintze at 8. Miniato Meetiog on Future Figh Dnergy Machines, Nlorence, Ifaly, 1984.

[32] The OPAT Detector Technical Propocal, GBRN/LSPC/82-1 LEPC/P 3.

[0S] Private cominumiedion with De. G. Viertel and J. Pehlman. 
[34] R.D. Hake and A.V. Phelps; Phys. Rev, 1334 (1984) a75.

[35] General overvlew can be found in A. Peirert and F. Bavli, CERN 84-08 (1984).

[38] G. Bchults and J. Gresver, Nucl. Inotrum. Mothoda 151 (1978) 413.

[37] A. Breskin, G. Charpak and F. Savit, Nucl. Inetrum. Methoda 136 (1967) 497.

[38] D. Bettoni et al, presented at 9. Mltiato Meating on Future High Energy Machines, Florence, Italy, 1984.

[aD] V. Palladino and B. Sadonlet, Nucl. Instrum. Methode 128 (1975) 323.

[40] Compilation taken from Paceedings of the SLC Workehop on Bxperimental Use of the 8LAC Linear Collider, SLAC-24J, 1982.

[41] This concept was originally wed at 1 atm by the HAS experiment at SLAC. The MAC teet results published in SLAC-PUB-3390, 1984.

[42] A. Wogrer, pelvate communication.

[43] M. Matobs et al., IEEE Trand. N9-32 (1985).

|14] E.F.W. Sadrozinaki, Sunte Crus University prepriat, SCIPP-84/28.

(15) D. Smith, private communiteation.

[46] V. Commichas at al, Aachen University preprint, PITHA 84-34.

[47] J. Jaros, privete commenication.

(19) M. Basile of al, CBRN-EP/85-40.

[49] J. Futh and D. Nygren, TPC-LBL-B5-7.

[BC] C.C. Yousg, private communicatlon. 
Table 1

\begin{tabular}{|c|c|c|c|c|c|c|}
\hline Tripe av tall & Pressure & Gas & $\begin{array}{l}\text { Type of } \\
\text { Electronics }\end{array}$ & $\begin{array}{l}\text { Resolution } \\
\text { ( } \omega / \text { Drift Diat.) }\end{array}$ & Experiment & $\begin{array}{c}\text { Type of } \\
\text { Measurement }\end{array}$ \\
\hline Aytinatrical & $\begin{array}{l}1 \text { atm } \\
1.5-2 \text { atm } \\
1 \text { atm } \\
1 \text { atm }\end{array}$ & $\begin{array}{l}\text { hot } \\
\text { cool } \\
\text { hot } \\
\text { cool }\end{array}$ & $\begin{array}{l}\text { Leading Edge } \\
\text { Leading Edge } \\
\text { Leading Edge } \\
\text { Leading Edge }\end{array}$ & $\begin{array}{l}\geq 80 \mu \mathrm{m} / 5 \mathrm{~mm} \\
40-100 \mu \mathrm{m} / 5 \mathrm{~mm} \\
\geq 30 \mu \mathrm{m} / 2 \mathrm{~mm} \\
\geq 30 \mu \mathrm{m} / 5 \mathrm{~mm}\end{array}$ & $\begin{array}{l}\text { Mark II } \\
\text { AfRGUS } \\
\text { MAC } \\
-\end{array}$ & $\begin{array}{c}\text { Phyaics }[25] \\
\text { Physies }[26] \\
\text { Physics }[41\} \\
\text { Test }[46]\end{array}$ \\
\hline Jet & $\begin{array}{l}4 \text { atm } \\
4 \text { atm } \\
6.1 \text { atm } \\
4 \text { atm } \\
1 \text { atm } \\
3 \text { atm }\end{array}$ & $\begin{array}{l}\text { hot } \\
\text { hot } \\
\text { hot } \\
\text { hot } \\
\text { cool } \\
\text { hot }\end{array}$ & $\begin{array}{c}\text { Leading Edge } \\
\text { Leading Edge } \\
\text { Leading Edge } \\
\text { IoO MEI FADC } \\
\text { Leading Edge } \\
\text { Leading Edge }\end{array}$ & $\begin{array}{c}23 \mu \mathrm{m} / 4 \mathrm{~mm} \\
<55 \mu \mathrm{m} / 8 \mathrm{~mm} \\
22 \mu \mathrm{m} / 2 \mathrm{~mm} \\
70-60 \mu \mathrm{m} / 1 \mathrm{~cm} \\
\sim 60 \mu \mathrm{m} / 1 \mathrm{~cm} \\
\sim 40-50 \mu \mathrm{m} / 1 \mathrm{~cm}\end{array}$ & $\begin{array}{c}- \\
\text { NA27, CERN } \\
- \\
\text { OPAL } \\
\text { SID \#1 } \\
\text { UA-1 }\end{array}$ & $\begin{array}{l}\text { Test [18] } \\
\text { Test } \\
\text { Teat [19] } \\
\text { Test [15] } \\
\text { Test [35] } \\
\text { Test [45] }\end{array}$ \\
\hline $\begin{array}{l}\text { Time Expansion } \\
\text { (TEC) }\end{array}$ & $\begin{array}{l}2 \mathrm{~atm} \\
2.7 \mathrm{~atm}\end{array}$ & $\begin{array}{l}\text { cool } \\
\text { cool }\end{array}$ & $\begin{array}{c}\text { Lending Edge } \\
\text { I00 MFz FADC } \\
\text { Leading Edge } \\
\end{array}$ & $\begin{array}{l}<40 \mu \mathrm{mm} / 1 \mathrm{~cm} \\
\sim 30 \mu \mathrm{m} / 1 \mathrm{~cm} \\
\sim 30 \mu \mathrm{m} / 1 \mathrm{~cm}\end{array}$ & $\begin{array}{c}\text { LEP3 } \\
- \\
- \\
\end{array}$ & $\begin{array}{l}\text { Test [14] } \\
\text { Test [43] }\end{array}$ \\
\hline $\begin{array}{l}\text { Semple Length } \\
\text { Restricting }\end{array}$ & $\begin{array}{l}4 \text { atin } \\
1 \text { atin }\end{array}$ & $\begin{array}{l}\text { cool } \\
\text { cool }\end{array}$ & $\begin{array}{l}\text { Leading Edge } \\
\text { Leading Edge }\end{array}$ & $\begin{array}{l}\leq 30 \mu \mathrm{m} / 1 \mathrm{~cm} \\
\sim 65 \mu \mathrm{m} / 1 \mathrm{~cm}\end{array}$ & $\begin{array}{c}- \\
\mathrm{NA3A}, \mathrm{GERN}\end{array}$ & $\begin{array}{l}\text { Test [11] } \\
\text { Test [38] }\end{array}$ \\
\hline Special Foctusing & $\begin{array}{l}1 \text { atm } \\
1 \text { atm } \\
3 \text { atm }\end{array}$ & $\begin{array}{l}\text { cool } \\
\text { cool } \\
\text { cool }\end{array}$ & $\begin{array}{l}\text { Leading Edge } \\
\text { Leading Edge } \\
\text { Leading Edge }\end{array}$ & $\begin{array}{l}\sim 45 \mu \mathrm{m} / 1 \mathrm{~cm} \\
\sim 65 \mu \mathrm{m} / 1 \mathrm{~cm} \\
\sim 35 \mu \mathrm{m} / 1 \mathrm{~cm}\end{array}$ & $\begin{array}{c}\text { SLD \#2 } \\
\text { NA34, CERN } \\
\text { Mark II }\end{array}$ & $\begin{array}{l}\text { Test [50] } \\
\text { Test [13] } \\
\text { Test [47] }\end{array}$ \\
\hline
\end{tabular}


Table 2

\begin{tabular}{|c|c|c|c|c|c|c|}
\hline \multirow[b]{2}{*}{$\begin{array}{l}\text { Type of } \\
\text { Chamber }\end{array}$} & \multirow[b]{2}{*}{$\begin{array}{l}\text { Drift } \\
\text { Length }\end{array}$} & \multirow[b]{2}{*}{$\begin{array}{c}\text { Average } \\
\text { Drift } \\
\text { Velocity }\end{array}$} & \multirow[b]{2}{*}{$\begin{array}{l}\text { Total } \\
\text { Drift } \\
\text { Time } \\
\end{array}$} & \multicolumn{3}{|c|}{ Spatial Error Due To } \\
\hline & & & & $\begin{array}{c}\text { Error In } \\
v \text { or } t \\
(1 / 1000)^{*}\end{array}$ & $\begin{array}{c}\text { Error In } \\
\qquad \begin{array}{c}E^{*} \\
(1 / 1000)^{*}\end{array}\end{array}$ & $\begin{array}{c}\text { Error In } \\
\text { Gas Dersity } \\
(1 / 1000)^{*}\end{array}$ \\
\hline "Slow" Drift & $1 \mathrm{~cm}$ & $5 \mathrm{\mu m} / \mathrm{hs}$ & $2 \mu$ gec & $10 \mu \mathrm{m}$ & $10 \mu \mathrm{m}$ & $10 \mu$ 政 \\
\hline "Fast" Drift & $1 \mathrm{~cm}$ & $30-50 \mu \mathrm{m} / \mathrm{ns}$ & $\leq 200 \mathrm{~ns}$ & $10 \mu \mathrm{m}$ & $5 \times 10^{-3} \mu \mathrm{m}$ & $\sim 0$ \\
\hline
\end{tabular}

* Assumption 
Table 3

\begin{tabular}{|c|c|c|c|}
\hline Quantity & "Fast" Drift & $\begin{array}{c}\text { "Slow" Drift } \\
\text { (with "cool" gas) }\end{array}$ & $\begin{array}{c}\text { "Slow" Drift } \\
\text { (with "low" E) }\end{array}$ \\
\hline Gas & $00 \% \mathrm{Ar}+10 \% \mathrm{CB}_{4}$ & $90 \% \mathrm{CO}_{3}+10 \% \mathrm{C}_{4} \mathrm{H}_{10}$ & $90 \% \mathrm{Ar}+10 \% \mathrm{CH}_{\mathbf{4}}+$ Methylal \\
\hline Prossure & 4 & 2 & 2 \\
\hline$E$ & $4 \mathrm{kV} / \mathrm{cm}$ & $1.2 \mathrm{kV} / \mathrm{cm}$ & $200 \mathrm{~V} / \mathrm{cm}$ \\
\hline$\mu^{+}$ & $1.9 \mathrm{~cm}^{2} / V_{\mathrm{sec}}$ & $1.1 \mathrm{~cm}^{2} / V_{\mathrm{seC}}$ & $1.9 \mathrm{~cm}^{2} / V_{\text {sec }}$ \\
\hline$T^{+}(1 \mathrm{cmgap})$ & $1.3 \times 10^{-1} \mathrm{gec} / \mathrm{stm}$ & $7.6 \times 10^{-1} \mathrm{sec} / \mathrm{at} / \mathrm{II}$ & $2.6 \times 10^{-3} \mathrm{sec} / \mathrm{atm}$ \\
\hline$\varepsilon$ & $\sim 0.5^{*}$ & $\sim 0.1^{*}$ & $\sim 0.1^{*}$ \\
\hline$\rho^{+}$ & $2.6 \times 10^{-13} \mathrm{C} / \mathrm{cm}^{3} \cdot$ atm & $3 \times 10^{-13} \mathrm{C} / \mathrm{cm}^{3} \cdot \mathrm{atm}$ & $1 \times 10^{-12} \mathrm{C} / \mathrm{cm}^{3} \cdot \mathrm{atm}$ \\
\hline$|\Delta E / E|_{\text {max }}$ & $4 \times 10^{-4}$ & $1.4 \times 10^{-3}$ & $28 \times 10^{-3}$ \\
\hline$\Delta x$ & $\sim 0 \mu m$ & $\sim 15 \mu m$ & $\sim 280 \mu \mathrm{m}$ \\
\hline
\end{tabular}

* - Assumption

\section{DISCLAIMER}

This report was prepared as an sccount of wort sponsord by an agency of the United States Covernment. Neither the United States Government nor any agency thereof, nor any of their employees, makes any wurranty, express or implied, or anumes any legal liability or responsibility for the accuracy, completenese. or usefulness of any information, apparatus, product, or process fiselosed, of represents that its use would not infringe privately owned rights. Refereace herein to any specific commercial product, procest, or service by trade name, trademark, manufacturer, or otherwise does not necessarily constitute or imply its eadorsement, recommendition, or fevoring by the United States Government of any agency thereof. The viewg and opinions of authors expreased berein do not necessarily state or reflect those of the thited Sutes Governmeat or any agensy thereof. 
Tabla 4

\begin{tabular}{|c|c|c|c|}
\hline Timing Method & $\begin{array}{c}\sigma[\mathrm{ns}] \\
(1 \mathrm{~cm} \text { of drift })\end{array}$ & $\begin{array}{c}\sigma[\mu \mathrm{m}] \\
\text { (asoumg } 50.4 \mu \mathrm{m} / \mathrm{ns} \text { ) }\end{array}$ & $\begin{array}{l}\text { Relativa } \\
\text { Accuracy }\end{array}$ \\
\hline $\begin{array}{l}\text { Ref. Pulse - } 2 \text { FADC Bins } \\
\text { (equal weight) }\end{array}$ & 2.0 & 101 & $1.00 \pm 0.01$ \\
\hline Ref. Pulge - 3 FADC Bing & 2.3 & 116 & 1.15 \\
\hline Ref. Pulse - 4 FADC Bins & 2.4 & 121 & 1.18 \\
\hline Ref. Pulge - 5 FADC Bins & 2.6 & 131 & 1.30 \\
\hline Ref. Pulse - 6 FADC Bing & 2.8 & 141 & 1,42 \\
\hline $\begin{array}{l}\text { Ref. Pulse - } 10 \text { FADC BIns } \\
\text { (a) Weighted: } 9,6,3,2,6^{*} 1 \\
\text { (b) Weighted: } 5,4,3,2^{*} 1,5^{*} 0 \\
\text { (c) Weighted: } 20,5,3^{*} 1,5^{*} 0\end{array}$ & $\begin{array}{l}2.3 \\
2.3 \\
2.2\end{array}$ & $\begin{array}{l}116 \\
116 \\
111\end{array}$ & $\begin{array}{l}1.13 \\
1.16 \\
1.08\end{array}$ \\
\hline Maximum Peak Method & 5.1 & 257 & - \\
\hline $\begin{array}{l}\text { Center of Gravity } \\
\text { (average over } 200 \mathrm{~ns} \text { ) }\end{array}$ & 4,0 & 202 & - \\
\hline Spline Fit & 3.0 & 151 & - \\
\hline
\end{tabular}

Note:

1. Best algorithm for short drift distances ( $\leq 3 \mathrm{~cm}$ ) is a simple reference timing with two equally weighted FADC bins.

2. Further reduction in resolution of about $0.2 \mathrm{~ns}(10 \mu \mathrm{m})$ can be obtained if the cross-talk compensation would be implamented. 
Table 6

\begin{tabular}{|c|c|c|c|c|c|c|c|c|}
\hline Type of Cell & $\begin{array}{l}\text { Pressure } \\
\text { (ntm) }\end{array}$ & $\begin{array}{c}\text { Effect } \\
\text { Sample } \\
\text { Sleded } \\
\text { (mm) }\end{array}$ & $\begin{array}{l}n N n p \\
(\#)\end{array}$ & $\begin{array}{c}F= \\
\frac{\operatorname{ag}}{\sqrt{\ln (\eta \pi n p)}}\end{array}$ & $\begin{array}{c}\text { Average } \\
\text { Drif } \\
\text { (cm) }\end{array}$ & $\begin{array}{c}\sigma_{L}(1 \text { alectron }) \\
\text { at } 1 \text { atm } \\
(\mu \mathrm{m} / \sqrt{\mathrm{cm}})\end{array}$ & $\begin{array}{c}\sigma_{\text {difrualon }} \\
E_{4}(z) \\
(\mu \mathrm{m})\end{array}$ & $\sigma_{\text {expurfment }}$ \\
\hline Jet $\mid 18\}$ & 1.0 & $\sim 0.8$ & 33 & 0,49 & 0.4 & 120 & 19 & 23 \\
\hline Mlero-Jet [19] & 6.1 & $\sim 0.2$ & 11 & $\mathbf{0 . 5 9}$ & 0.2 & $\geq 125$ & $16^{3}$ & 29 \\
\hline Jet [24] & 1.0 & $\sim 1.0$ & ? & 0.61 & 1.0 & 80 & 49 & 60 \\
\hline Sample Restrict [11] & 4.0 & $\sim 0.8$ & 29 & 0.50 & 1,0 & 70 & $1 T$ & 30 \\
\hline Special Facus [13] & 1.0 & $\sim 1.5$ & 14 & 0.86 & 1.0 & 70 & 12 & 60 \\
\hline TEC [14] & 20 & $\approx 2.0$ & 36 & 0.48 & 1.0 & 100 & $\mathbf{3 1}$ & $40^{\circ}$ \\
\hline Jet [45] & 3.0 & $\sim 0.6$ & 27 & 0.54 & 0.5 & 200 & 44 & $40-50$ \\
\hline
\end{tabular}

(a) In calculation usume the first electron timing.

(b) The moasuremente uned the low threshold leading edge timing.

(c) Wo eannot use the en. (2) in this particular tase beesuse wo have not kopt

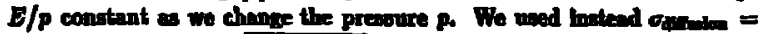
$F \times$ ot (1election) $\times \sqrt{(E / P)^{-3} X / \vec{E}}$, where of h normalined to $1 \mathrm{kV} / \mathrm{cm}$, $1 \mathrm{stm}$ and $1 \mathrm{cos}$ of drift $E=14.6 \mathrm{kV} / \mathrm{cm}, \sigma_{\mathrm{L}}=130 \mu \mathrm{m} / \sqrt{\mathrm{cm}}$

(d) The effective anple aine in estimated from the Monto Carlo progrars (beo fig. 10).

(c) The teat had an equivalent threshold of $\sim 6$ electrons for the leading edge timing. 
Table 6

\begin{tabular}{|c|c|c|}
\hline \multirow{3}{*}{\multicolumn{2}{|c|}{ Thining Method }} & Realution (miarono) \\
\hline & & Deeign (a) Dexign (d) \\
\hline & & $0 \mathrm{deg} 10 \mathrm{deg} 0 \mathrm{deg} 10 \mathrm{deg}$ \\
\hline$(1)$ & $\begin{array}{l}\text { Flrat electron timing with intunitely fast } \\
\text { electroales }\end{array}$ & $20 \pm 3 \quad 34 \pm 3 \quad 25 \pm 2 \quad 32 \pm 3$ \\
\hline (2) & $\begin{array}{l}\text { Centroid timing with infinitely fast elec- } \\
\text { tronica (nvernge over the first } 100 \text { no only) }\end{array}$ & $\begin{array}{lll}7 \pm 1 & 14 \pm 2 \quad 12 \pm 1 \quad 13 \pm 1\end{array}$ \\
\hline (9) & $\begin{array}{l}\text { Leeding adge timing with the realietic } \\
\text { pulben (threchold } \sim 2-3 \% \text { of the average } \\
\text { amplituda) }\end{array}$ & $20 \pm 3 \quad 18 \pm 420 \pm 2 \quad 36 \pm 3$ \\
\hline (4) & $\begin{array}{l}\text { Centroid timing with the reslistic pulses } \\
\text { and 100 MFa digtizer (woe the simplecen- } \\
\text { troid thing) }\end{array}$ & $20 \pm 1 \quad 27 \pm 2 \quad 36 \pm 3 \quad 43 \pm 3$ \\
\hline
\end{tabular}

Note:

1. Simulation performed fro $4 \mathrm{~atm}$ preseure, $12 \mathrm{~mm}$ drift distance, $92 \% \mathrm{CO}_{2}$ $+\mathrm{B} \% \mathrm{C}_{1} \mathrm{H}_{20} \mathrm{gas}$ and the drift velocity $v=\mathbf{4 . 0 - 4 . 2}$ microns/ns.

2. The examples correspond to Gg. 35(a) and (d), 36(a) and (d); [Gs. 33(b) $\equiv \mathrm{Eg} . \mathbf{3 8}(\mathbf{a})]$.

3. The angle refers to an angle of the trask and the anode plare. 


\section{FIGURE CAPTIONS}

1. Characteristic energy, drift velocity and difusion (for $1 \mathrm{~cm}$ of drift and 1 atm pressure) in $\mathrm{CO}_{2}$ as a function of the electric field [34].

2. Diffusion for $1 \mathrm{~cm}$ drift and 1 atm pressure as a function of the electric field [11].

3. Characteristic energy as a function of the electric field in hot gas mixtures [39].

4. Difiusion for $1 \mathrm{~cm}$ drift and $\mathrm{I}$ atm pressure for typical hot gases [40].

5. Measured transverse and longitudinal diffusion in JADE gas [3].

6. Cajculated transverse and longitudinal difiusion in $90 \% \mathrm{Ar}+10 \% \mathrm{C}_{1} \mathrm{H}_{10}$ for $1 \mathrm{~cm}$ drift and $i$ atm $[4]$.

7. Influence of gas pressure on localization accuracy of a drift chamber [5].

8. The computer simulation of the drift pulses caused by particles in the microjet chamber [9].

9. Examples of the charge collection in typical drift chambers.

10. Schematic view of (a) isochronous and (b) nonisochronous charge collection. with indication of the effective Barnple length.

11. Schematic view of the nonisochronous charge collection in the jet chamber operating with $90 \% \mathrm{Ar}+10 \% \mathrm{C}_{4} \mathrm{H}_{10} \mathrm{gag}$ at 1 atm and $B=10 \mathrm{kG}$ [9]-

(a) The effect of diffusion and clustering on the drift pulse randomness (avalanche fluctuation and electronics response included).

(b) The effect of the impact parameter $(0$ and $6 \mathrm{~mm}$ ).

(c) The effect of the angle of the track ( $B=0 \mathrm{kG})[17]$.

12. The effect of the drift velocity behavior on the isochrony of the jet chamber. The drift time distribution gets narrower for the gas \#2 [17]. 
13. Cell configuration and measured spatial resolution of a simple wire as a function of gas pressuse in a high precision jet chamber [18].

14. Cell conffguration and measured spatial resolution of a bingle wire as a function of impact parameter in a micro-jet chamber $\left(90 \% \mathrm{Ar}+10 \% \mathrm{C}_{1} \mathrm{H}_{\mathrm{IO}}\right.$ gas waed) $[19]$.

15. Spatial resolution obtained in the SLD prototype \#1 (aimple jet chamber) in $92 \% \mathrm{CO}_{2}+8 \% \mathrm{C}_{4} \mathrm{H}_{10}$ at 1 atm using the leading edge timing [24]. The solid line in a fit of the form $\sqrt{C_{0}^{2}+C_{1}^{2} X}$ where $C_{0}=0.081$ and $C_{1}=63.5$ $\mu \mathrm{m}-\mathrm{cm}^{-1 / 2}$.

16. Spatial resolution in ARGUS vertex chamber [26].

17. Example of charge restricting geometry:

(a) The prototype configuration.

(b) Spatial resclution using a leading edge timiug as a function of impact parameter.

(c) Spatial resolution of the second track as a function of a distance from the flrst track.

(d) Efficiency to find the second track as a function of a distance from the flrst track.

(e) Future plan [11].

18. Example of a charge focusing geometry:

(a) Drift cell conflguration.

(b) Lines of equal drift time.

(c) Measured spatial resolution in this cell.

(d) The measured opatial resolution in cell as in fig. 17(e) with $2 \mathrm{~mm}$ restricting gBp [13].

19. (a) Example of a charge focusing geometry in the SLD prototype \#2 [21,50]. 
(b) Measured resalution in $\mathrm{B}_{2} \% \mathrm{CO}_{2}+8 \% \mathrm{O}_{4} \mathrm{H}_{10}$ at 1 atmo wing the luading edge timing. The smooth curve is the prediction of a computa Monts Gurlo simuintion [8]-

20. Time expancion chamber protolype [14].

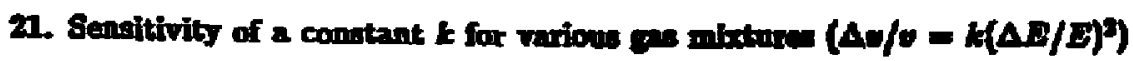
[20].

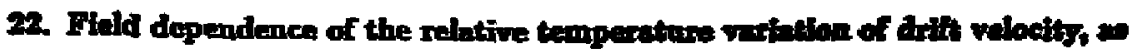

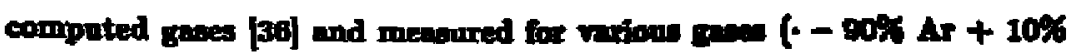

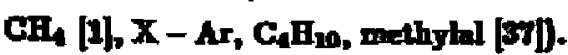

23. Schematic view of nonivochronous behavior of jet chamber like OPAL.

24. The principle of the method of timing with the FADC wing a reference pule. The method minimizes a quantity

$$
Q=\sum_{i=1}^{N} W_{i}\left[Y_{i}^{R B F}-Y T^{\mathrm{TDO}}\right]^{2}
$$

25. Measured opatial resolution using the FADC tingh for varioun operating poinks as a function of drift distance in the OPAL prototype [31\}.

26. Calculated transwerse and longitudinal diffusion in $90 \%$ Ar $+10 \%$ OH, for $1 \mathrm{~cm}$ drift and 1 atm [4]. Numbers correspond to various operatias pointa of fig. 25-1.

27. The simnlated timing resolution uaing a hypothetical infinitely fant electronies capable of digitiring every arriving electron bo jet chamber with $1 \mathrm{~mm}$ vire apacing, $90 \% \mathrm{Ar}+10 \% \mathrm{C}_{4} \mathrm{H}_{10}$ at $1 \mathrm{~atm}, B=10 \mathrm{kG}$ and $7.5 \mathrm{~mm}$ inqpact parameter [9].

28. (a) Lines of equal drift time in the time expanaton prototype [14].

(b) the schematic view of nonisochronous bohsvior in this cell. 
29. (a) Neansed spatial recolatlon of the time expansion chamber prototype at 1 and 2 atm (FADC timing) [14].

(b) Meanured apatial resolution of the tive expansiont chamber protolype for two timing methois (FADC and TDC timing). The TDC threshold correaponda to $\sim 6$ electronu [3:5].

30. Resulta from T2C tat [10] using the dimethyl ether gas and the lending edgit timint.

31. Principle of the rudilil diff chamber [49].

32. Reaulte from the Aschen Dniverilty teat [46]-

(a) Drith valocity as a function of a distance between the anode and the tesect.

(b) Meaured resolution using the TDC and FADC techniques.

33. Isochronous behavlor for varfous afternatives of the charge collection in the TEO chamber as aimulated by author for $92 \% \mathrm{CO}_{2}+8 \% \mathrm{C}_{4} \mathrm{H}_{10}, 2$ atm and $E \approx 1.1 \mathrm{kV} / \mathrm{cm}$ |voltages and wire geometry the same as in fig. 28(a)].

(a) Charge reatrieting geometry tolog foils with $1 \mathrm{~mm}$ gap.

(b) Adding 8 wise tato the ralddle of the gap, otherwise as point (a).

(c) $1 \mathrm{~mm}$ whe gep grid aystam.

34. Poselble veraion of an "ultimate" design using the TEC concept, the charge reotricting and the charge focusing geometry.

35. Drift time distributions for verious designs and several drift distances for

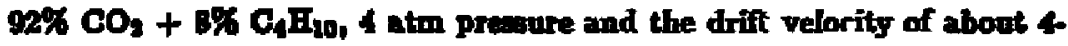
$4.2 \mathrm{~mm} / \mathrm{m}$ (the amount of lonization artificially increased for greater charity).

36. The mamo an fig. 35 but the track inclined by $10^{\circ}$ in respect to the arode plane. 


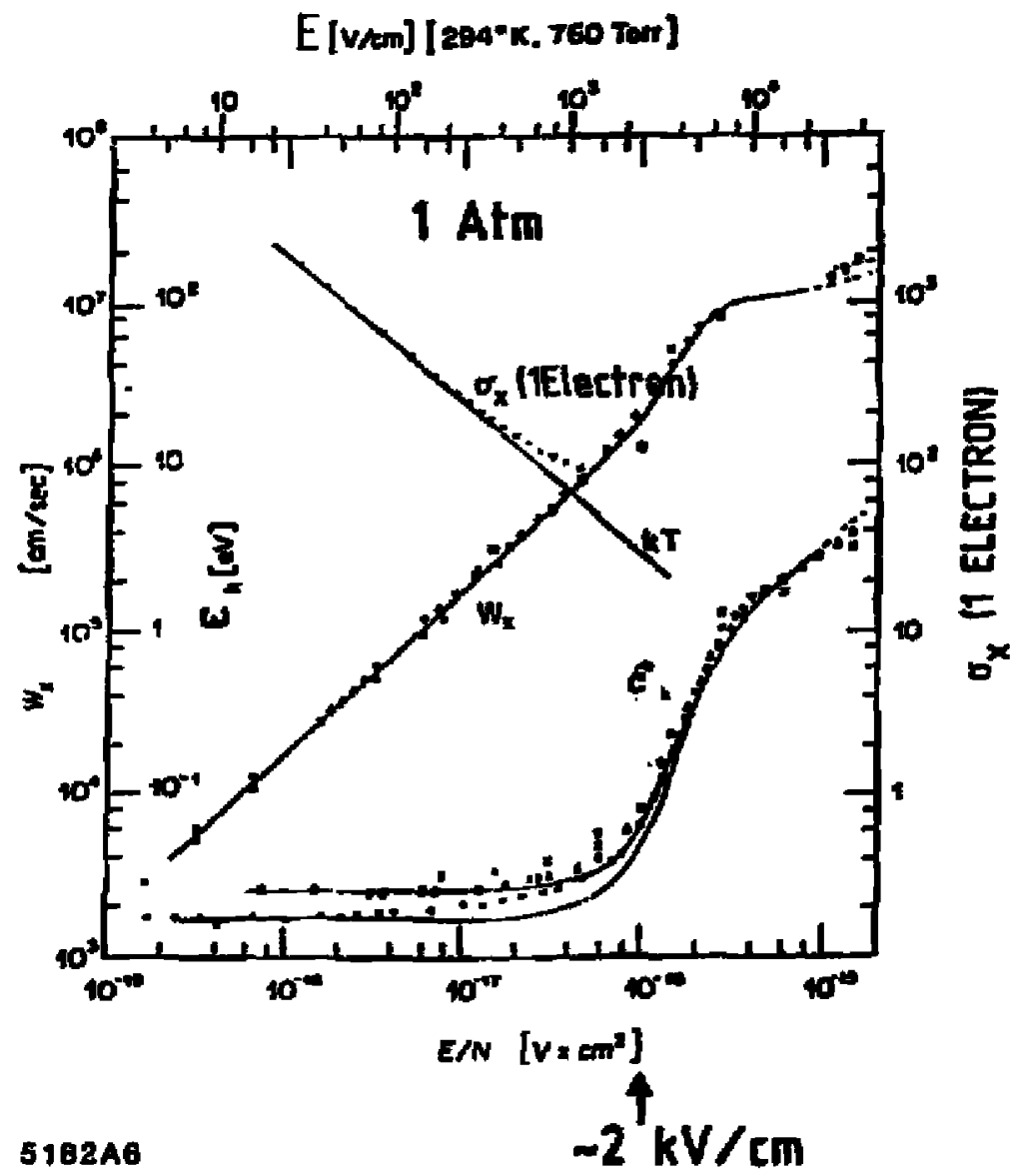

Fig. 1 


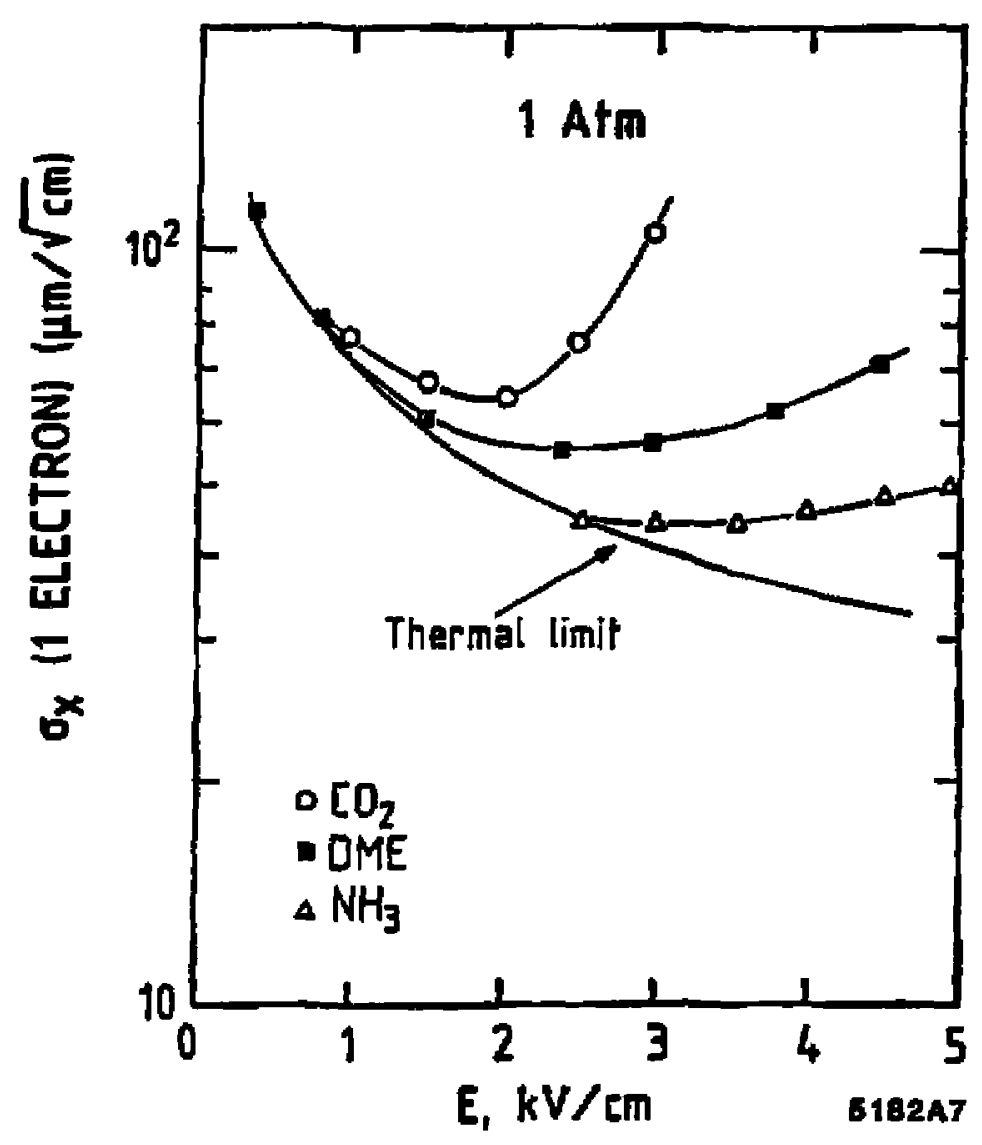

Fig. 2 


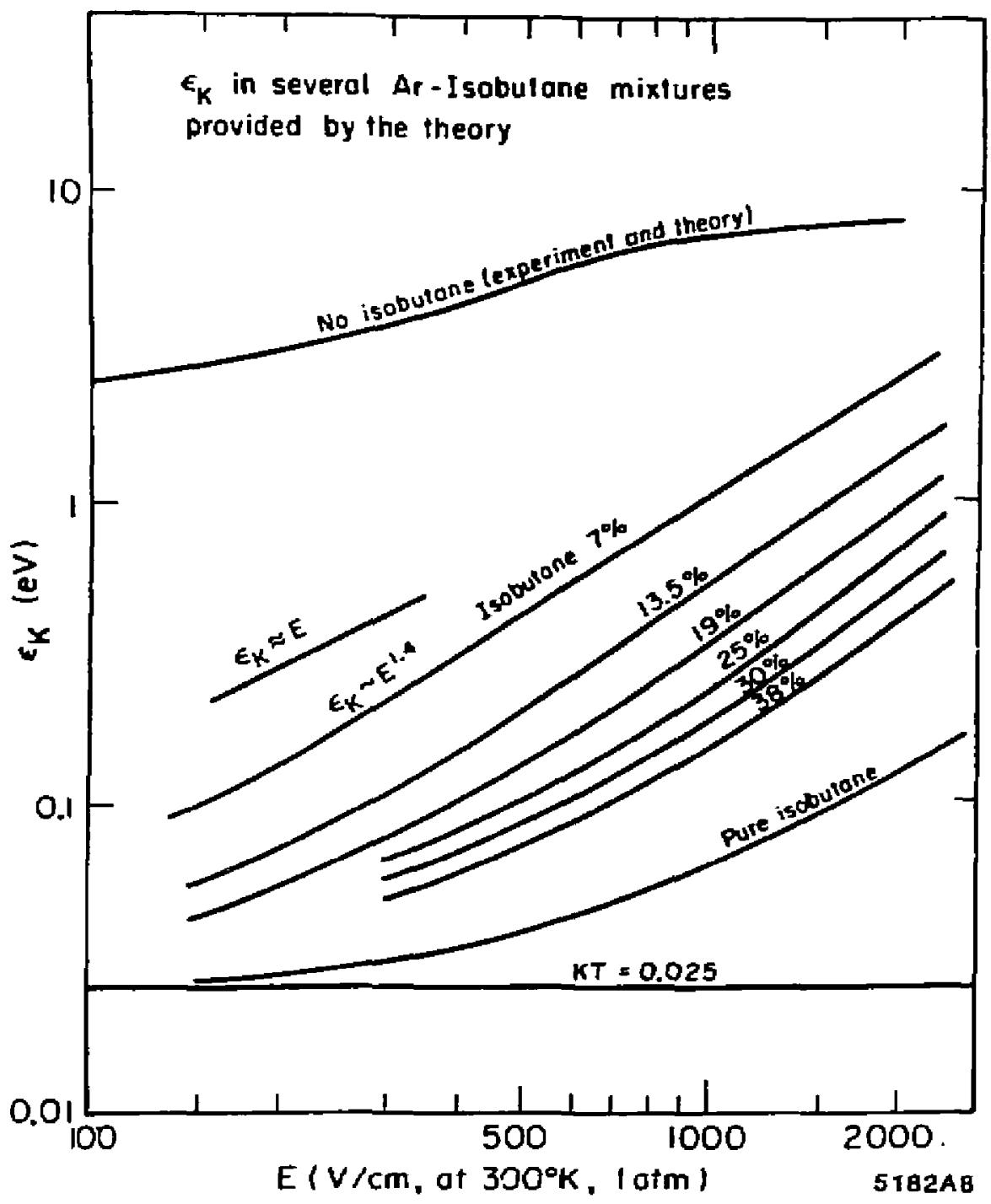

Fig. 3 


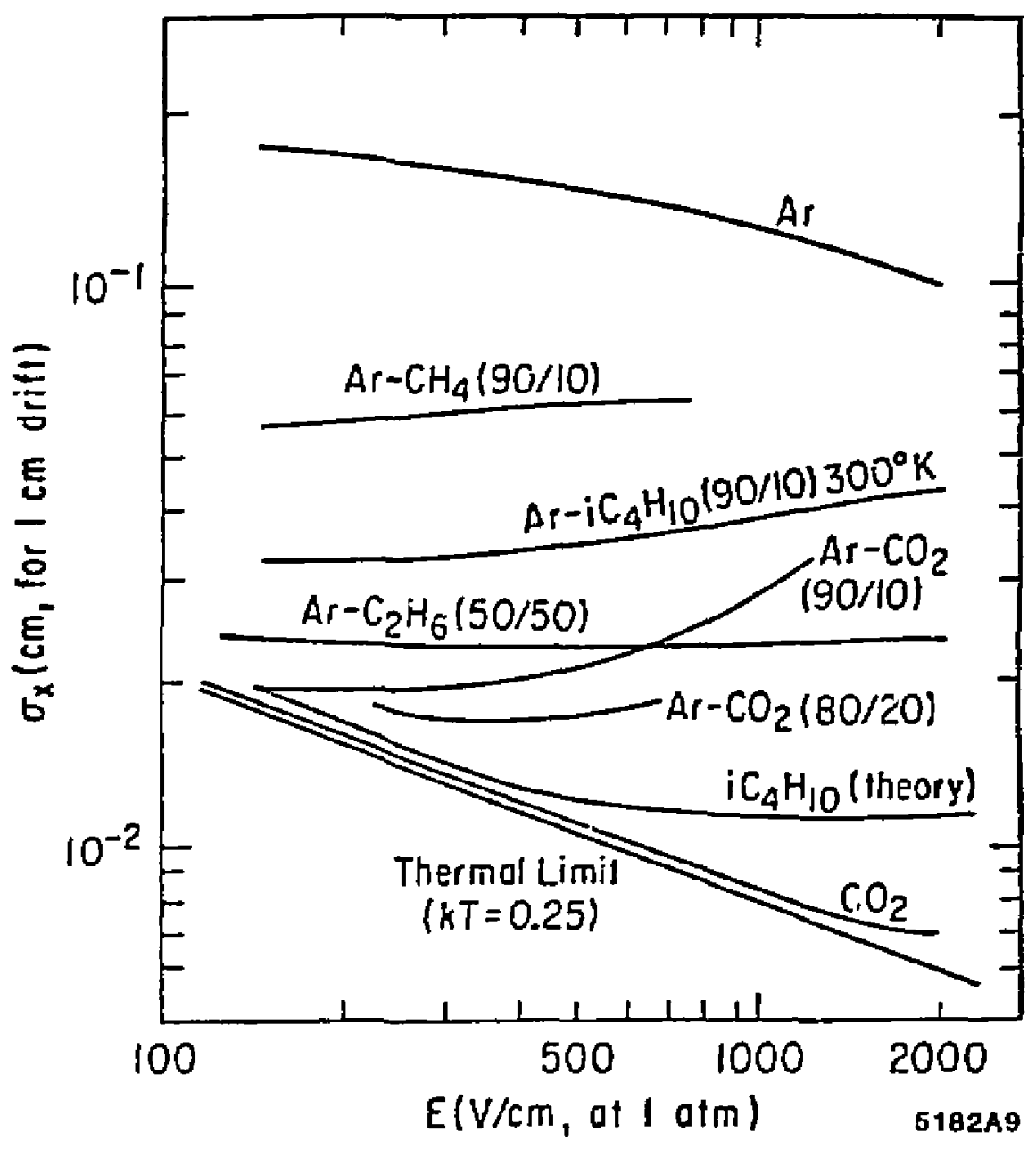

Fig. 4 


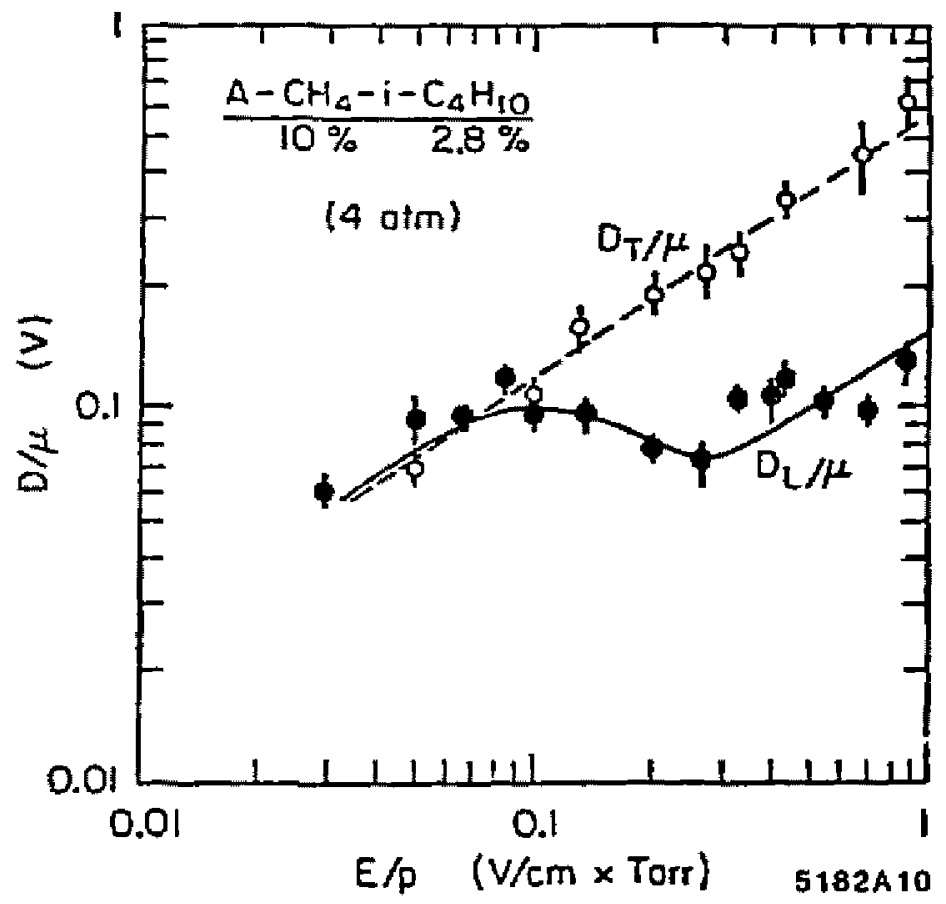

Fig. 5 


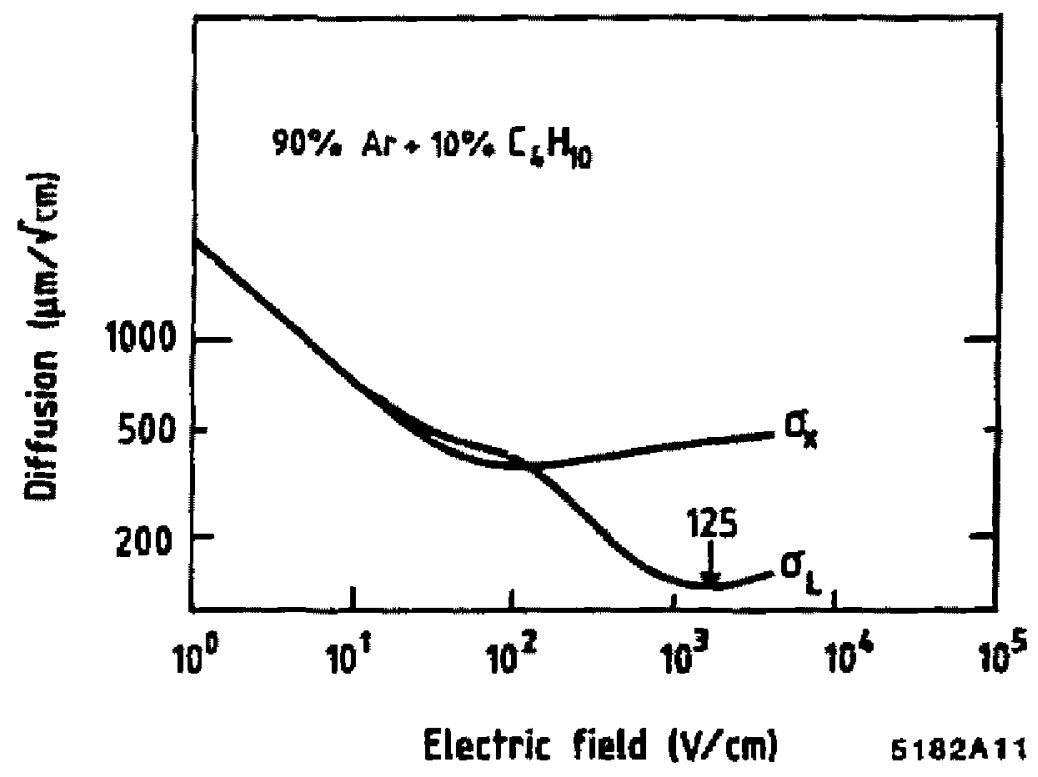

Fig. 6 


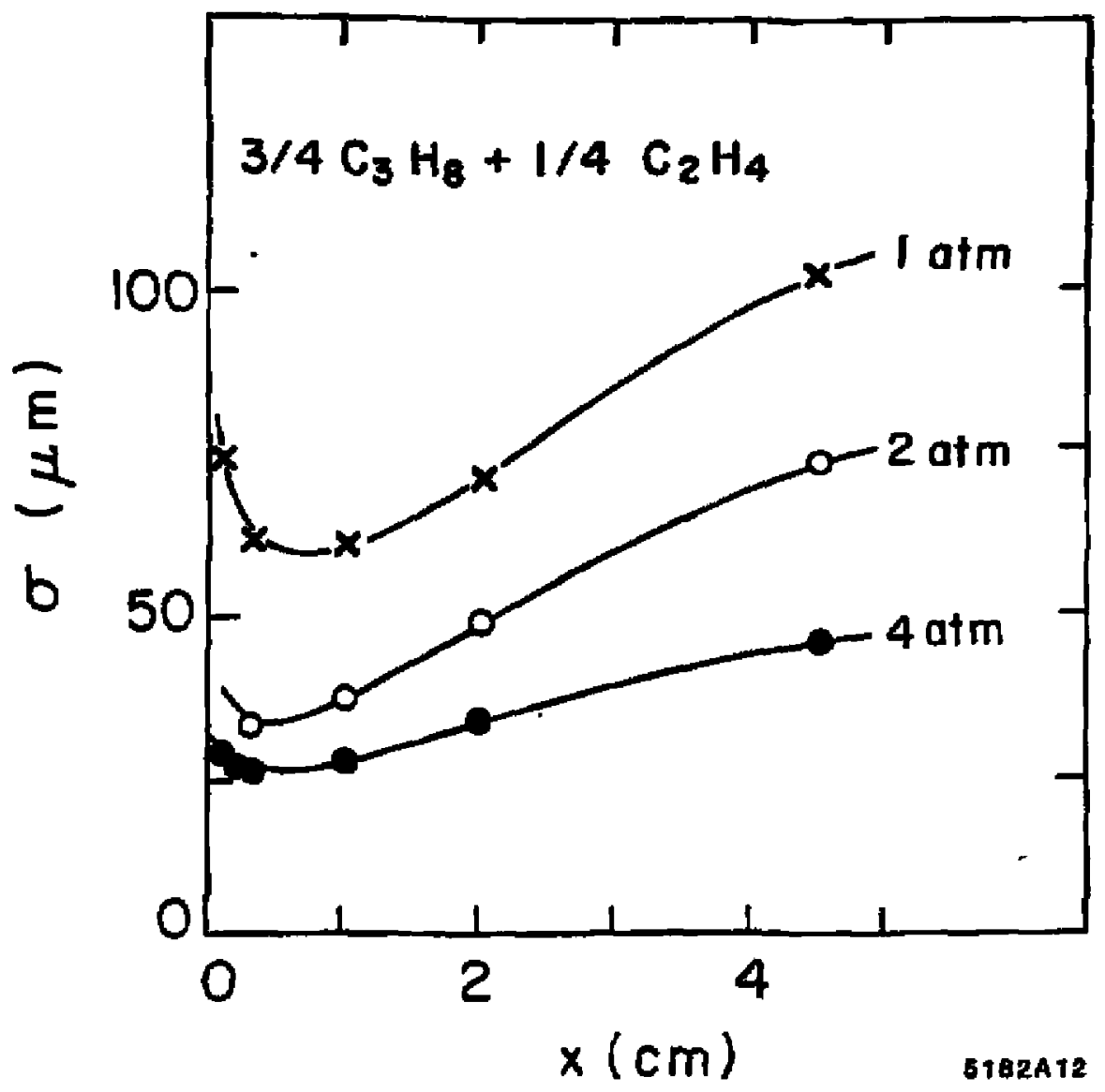

Fig. 7 


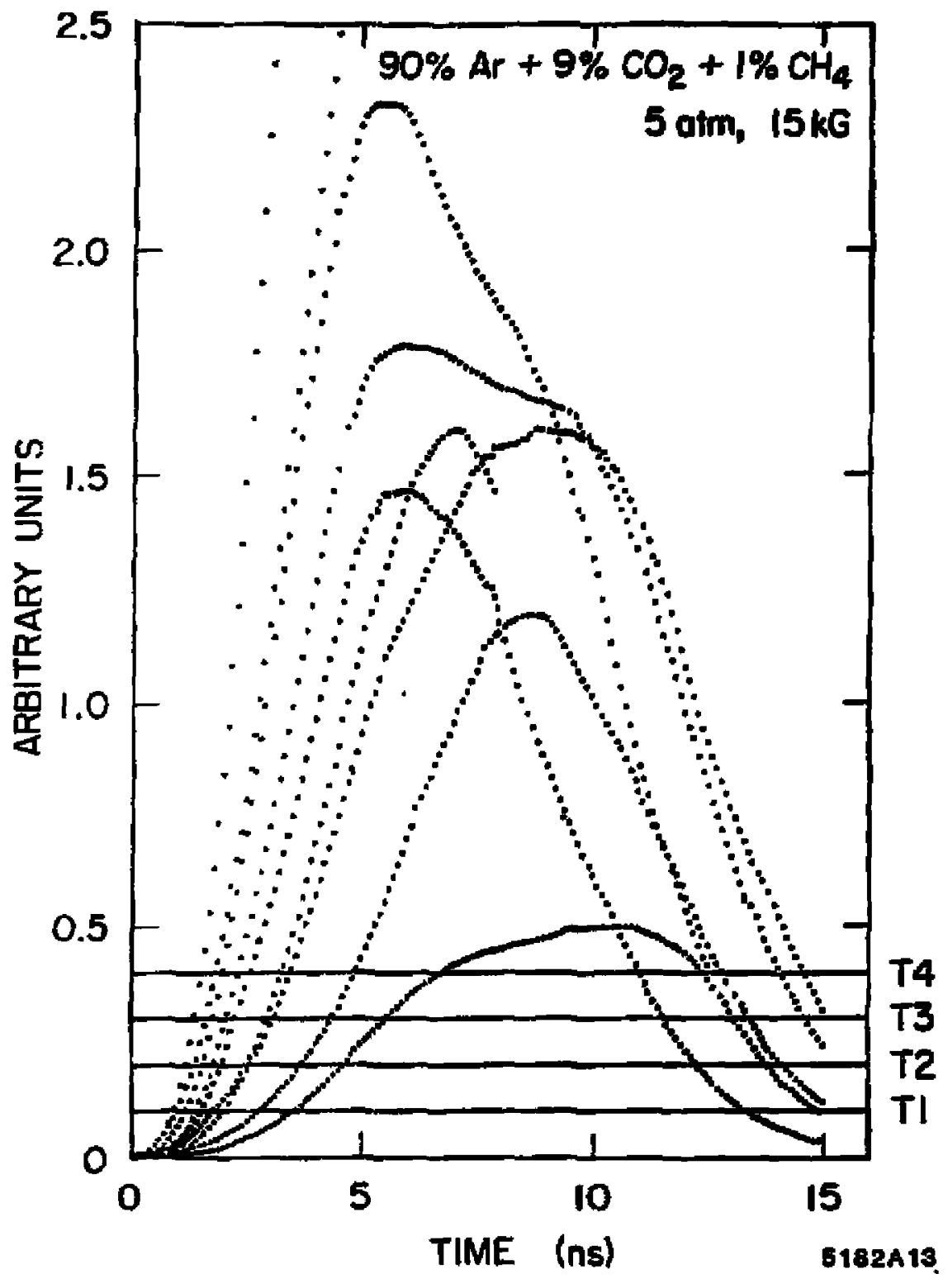

Fig. 8 


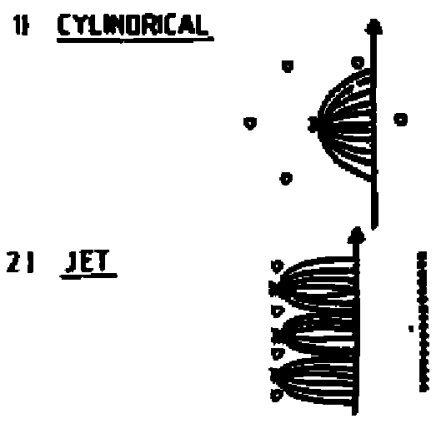

3) IET WITH FOCUSALT

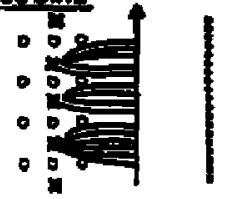

4) TIME EXFANSION ITEC

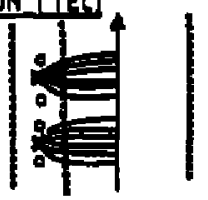

5) SAMPLE LENDTH RESTRICTINE

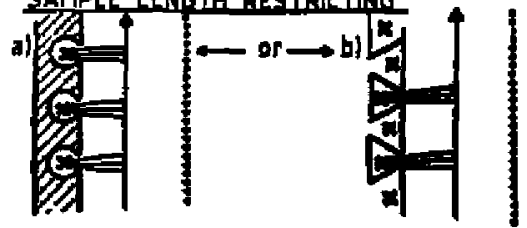

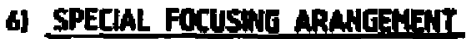

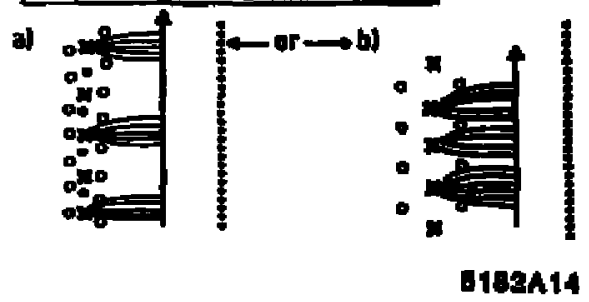

Fig. 9 
Position of trift electron along the sample

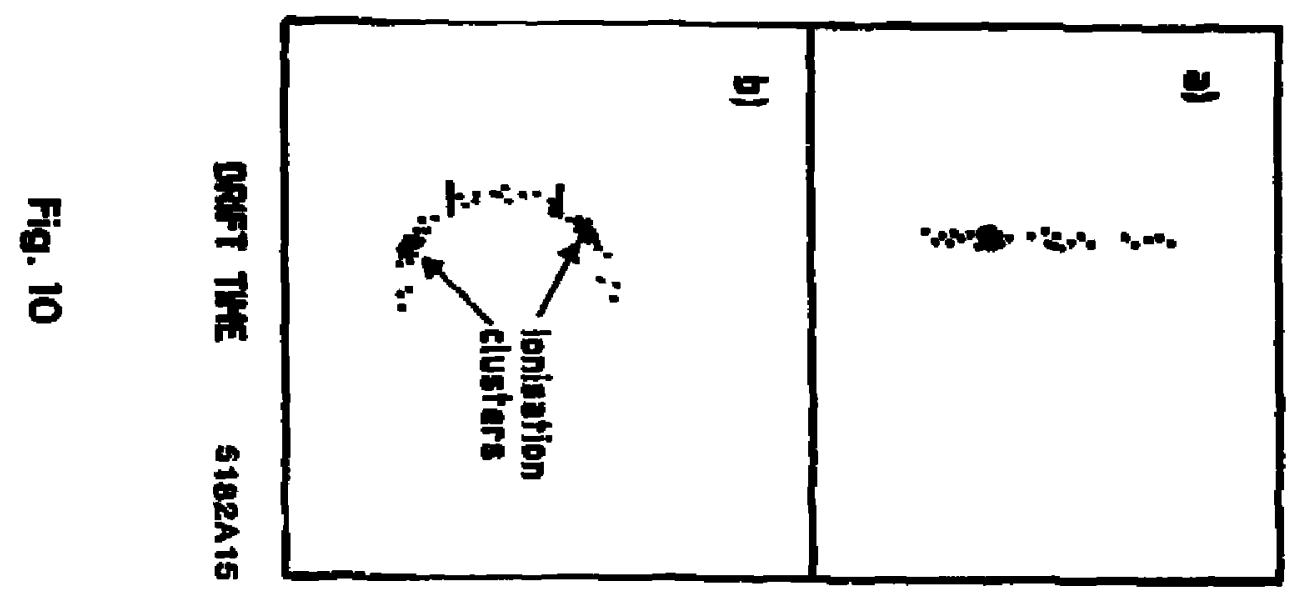




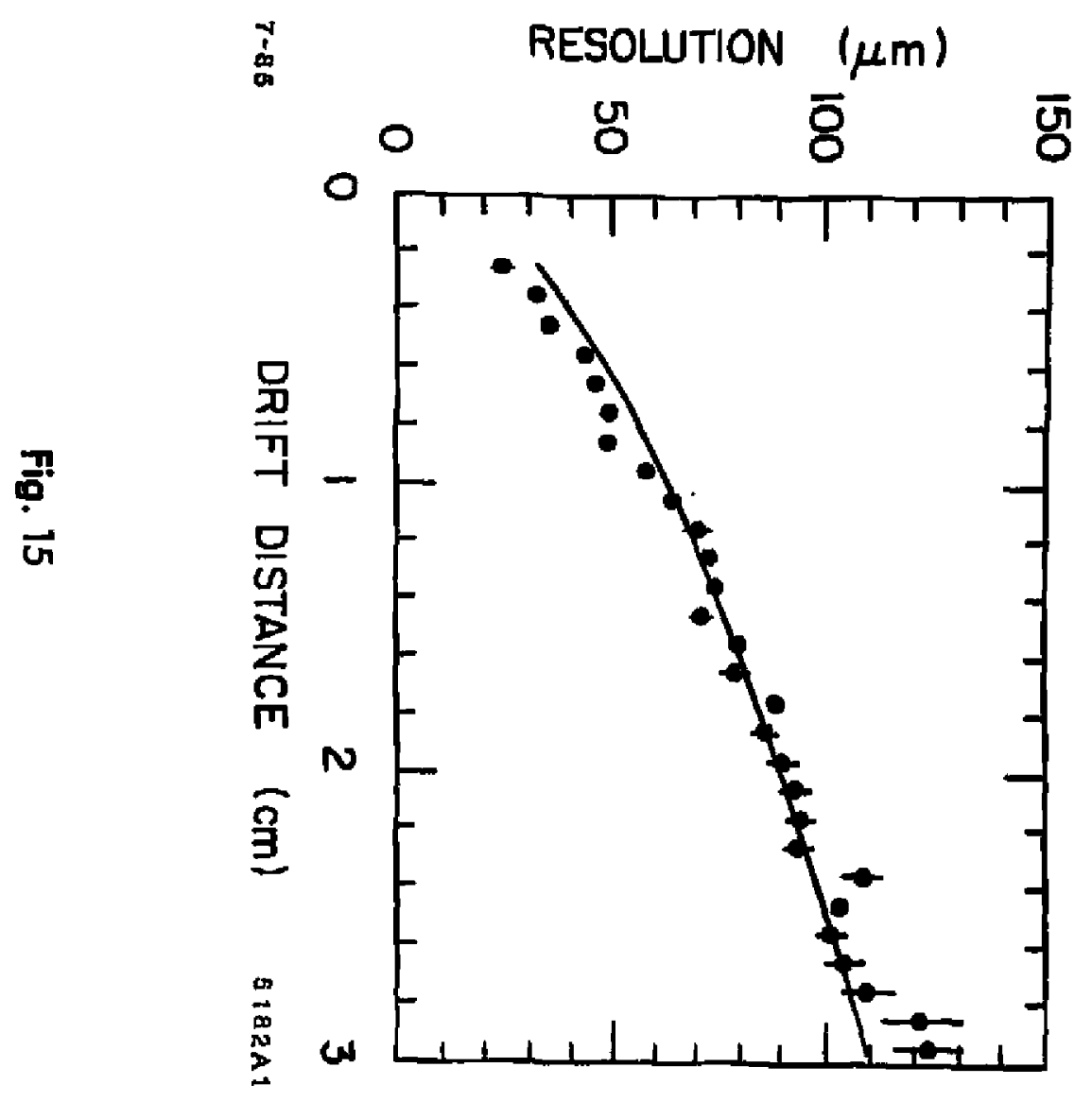




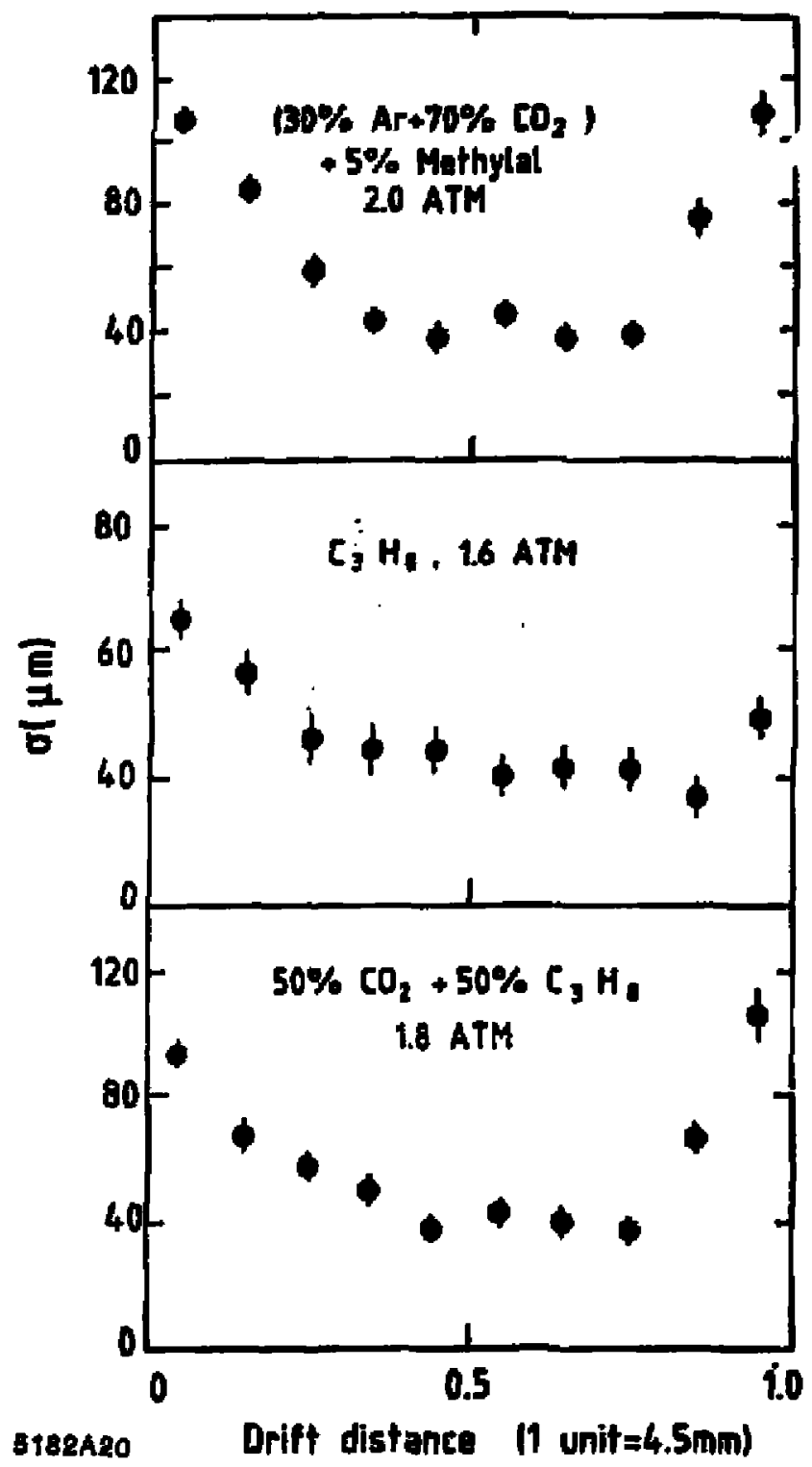

Fig. 16 

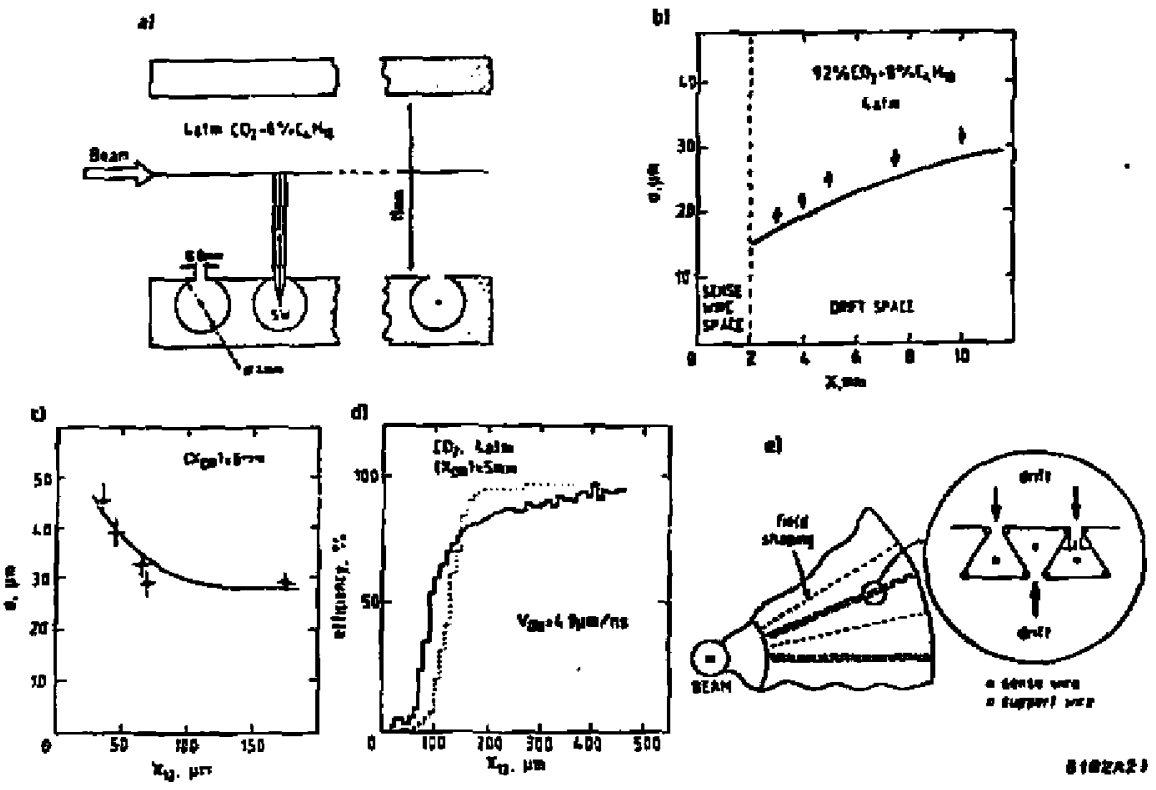

Fig. 17 


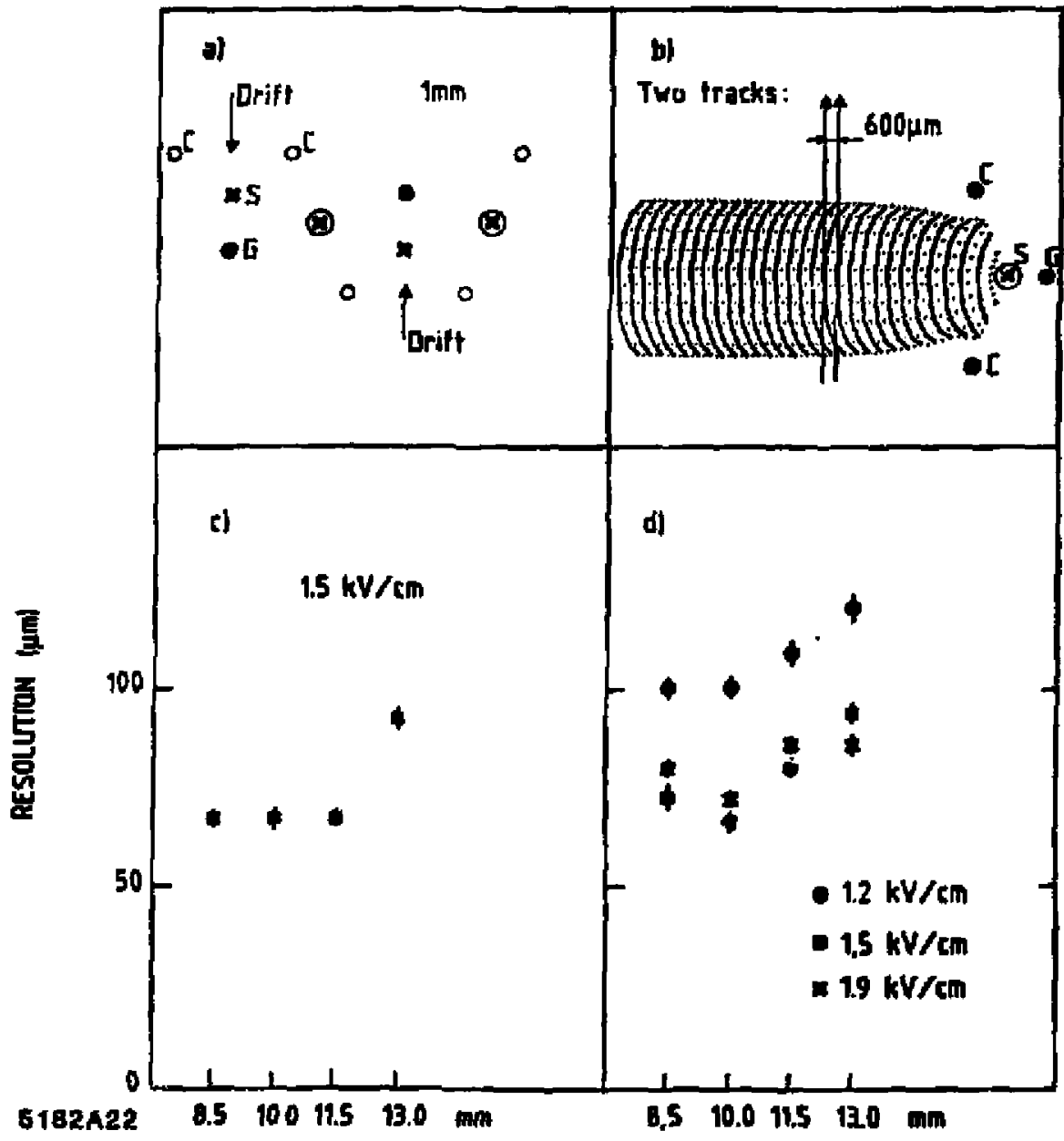

Fig. 18 
(0)
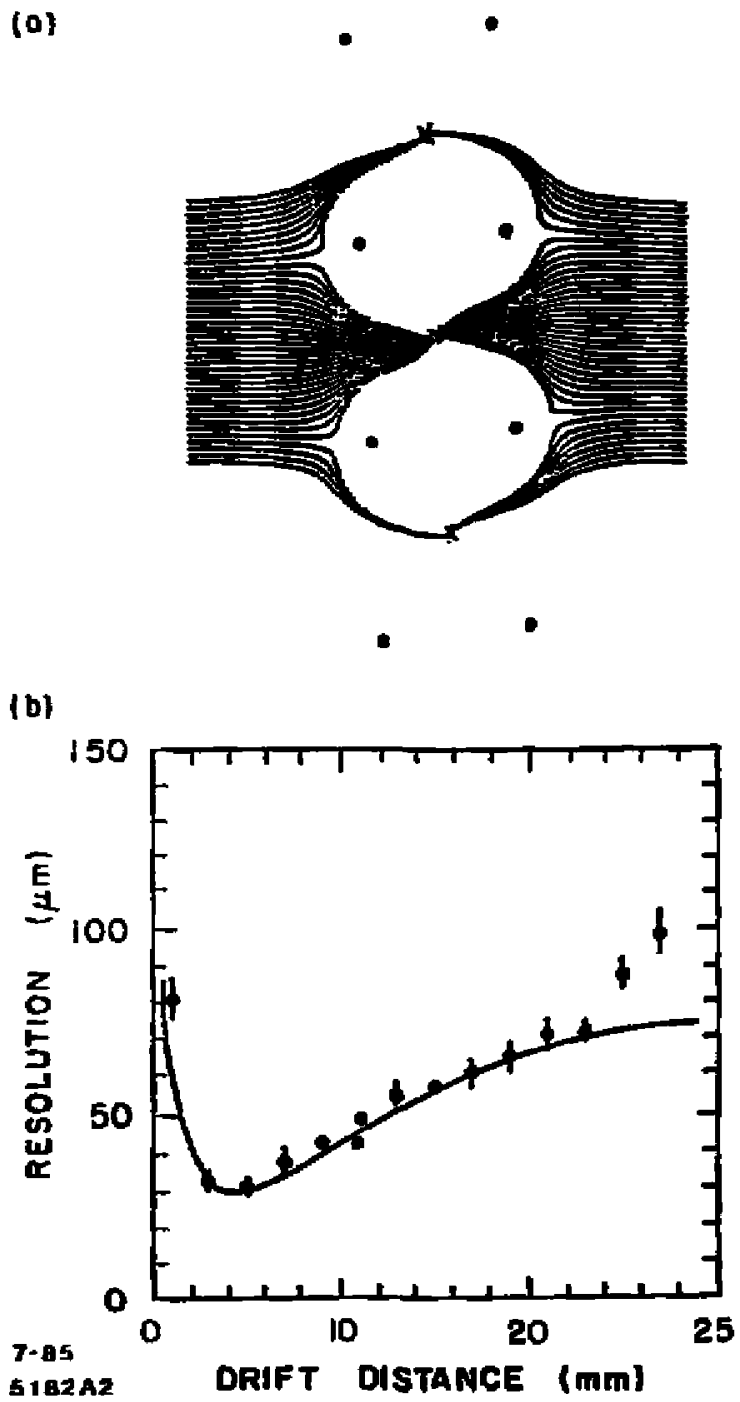

Fig. 19 


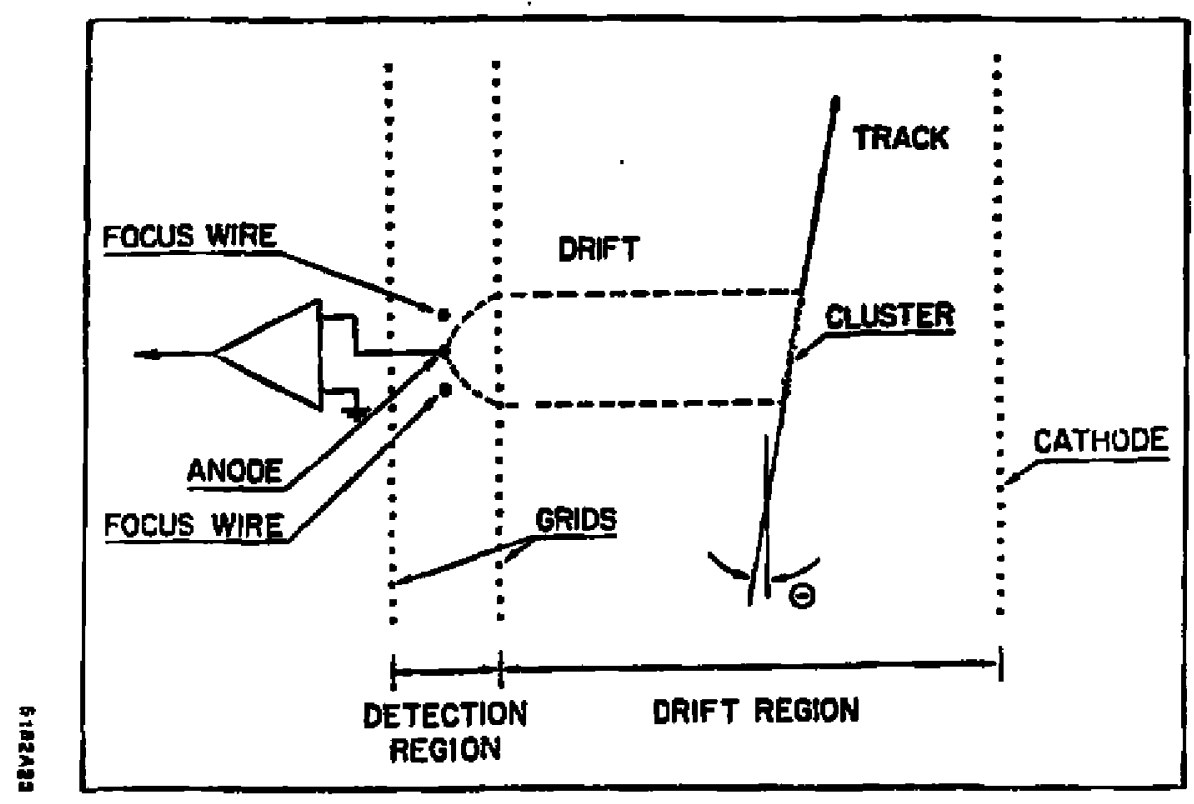

Fig. 20 


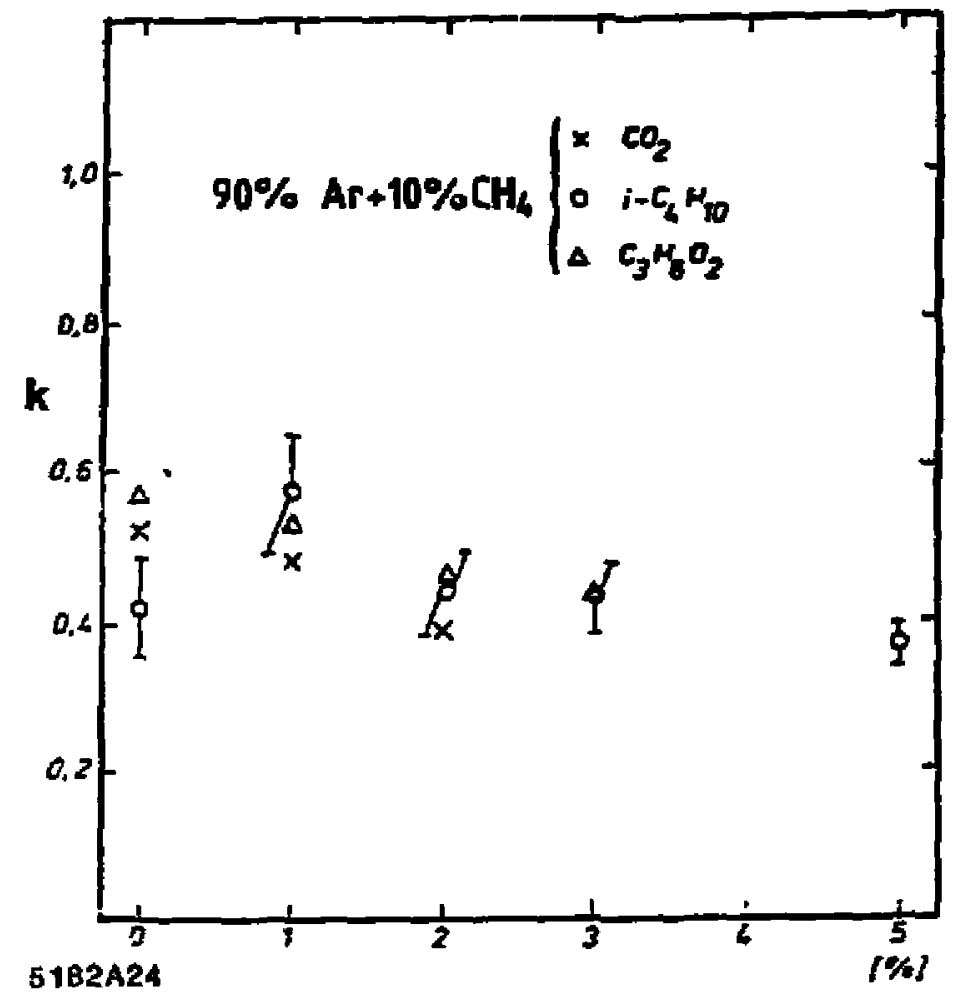

Fig. 21 


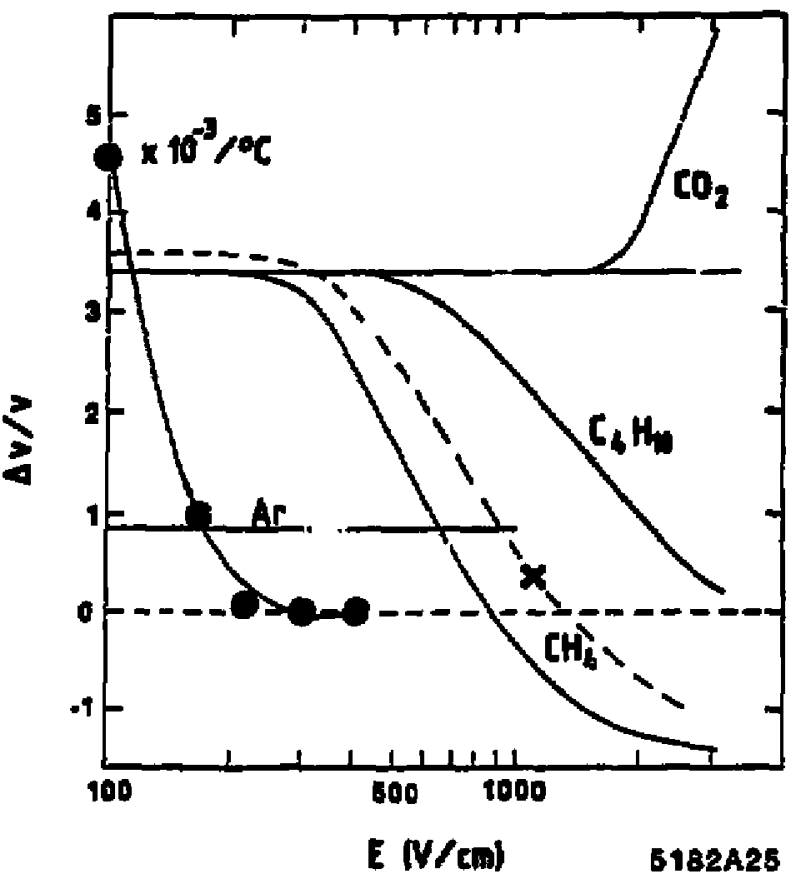

Fig. 22 


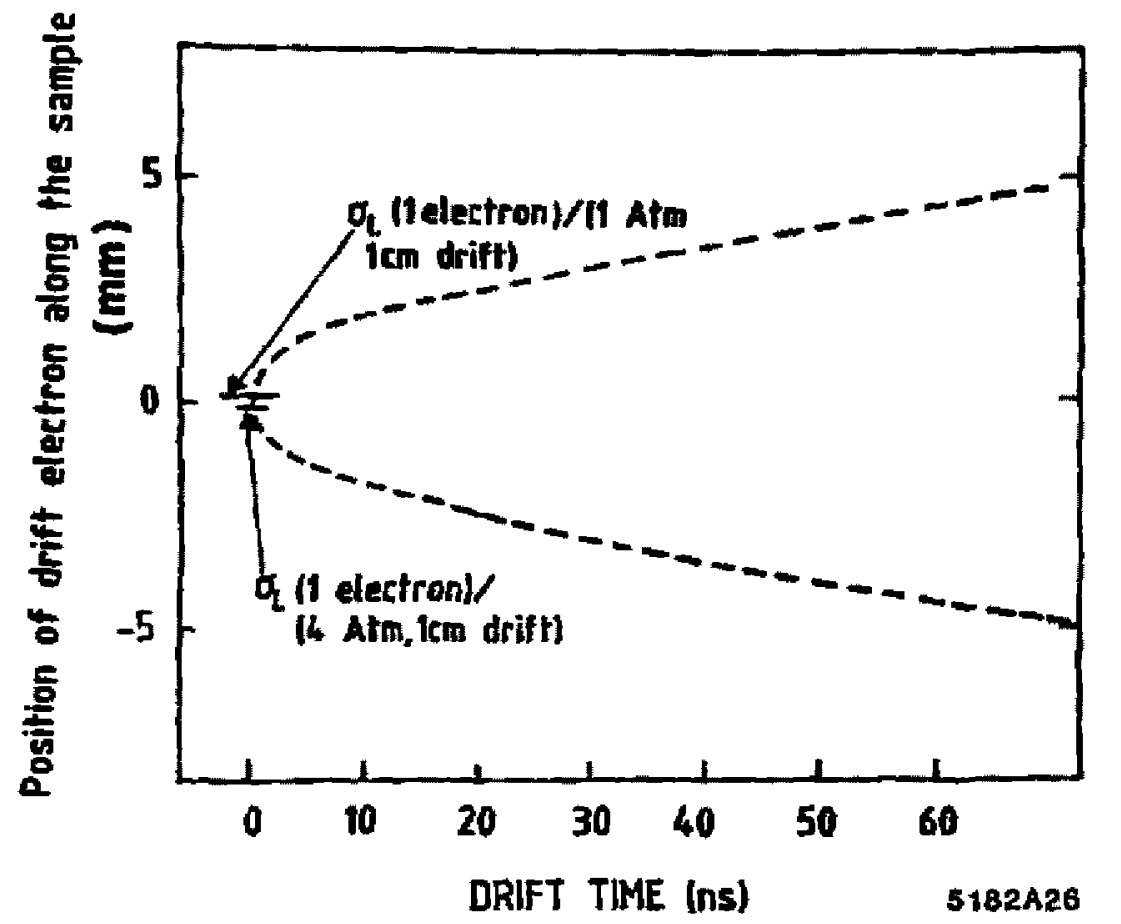

Fig. 23 


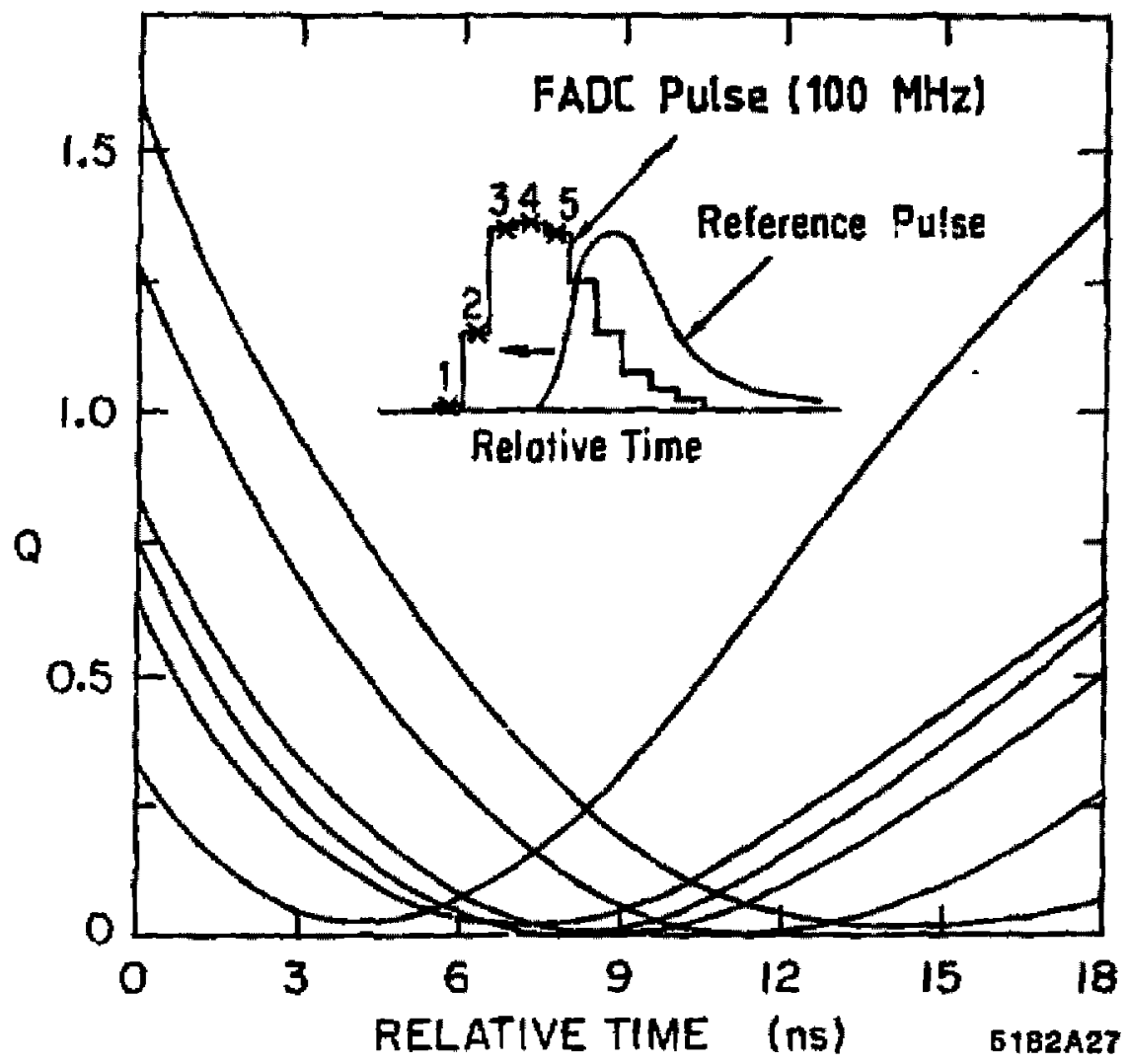

Fig. 24 

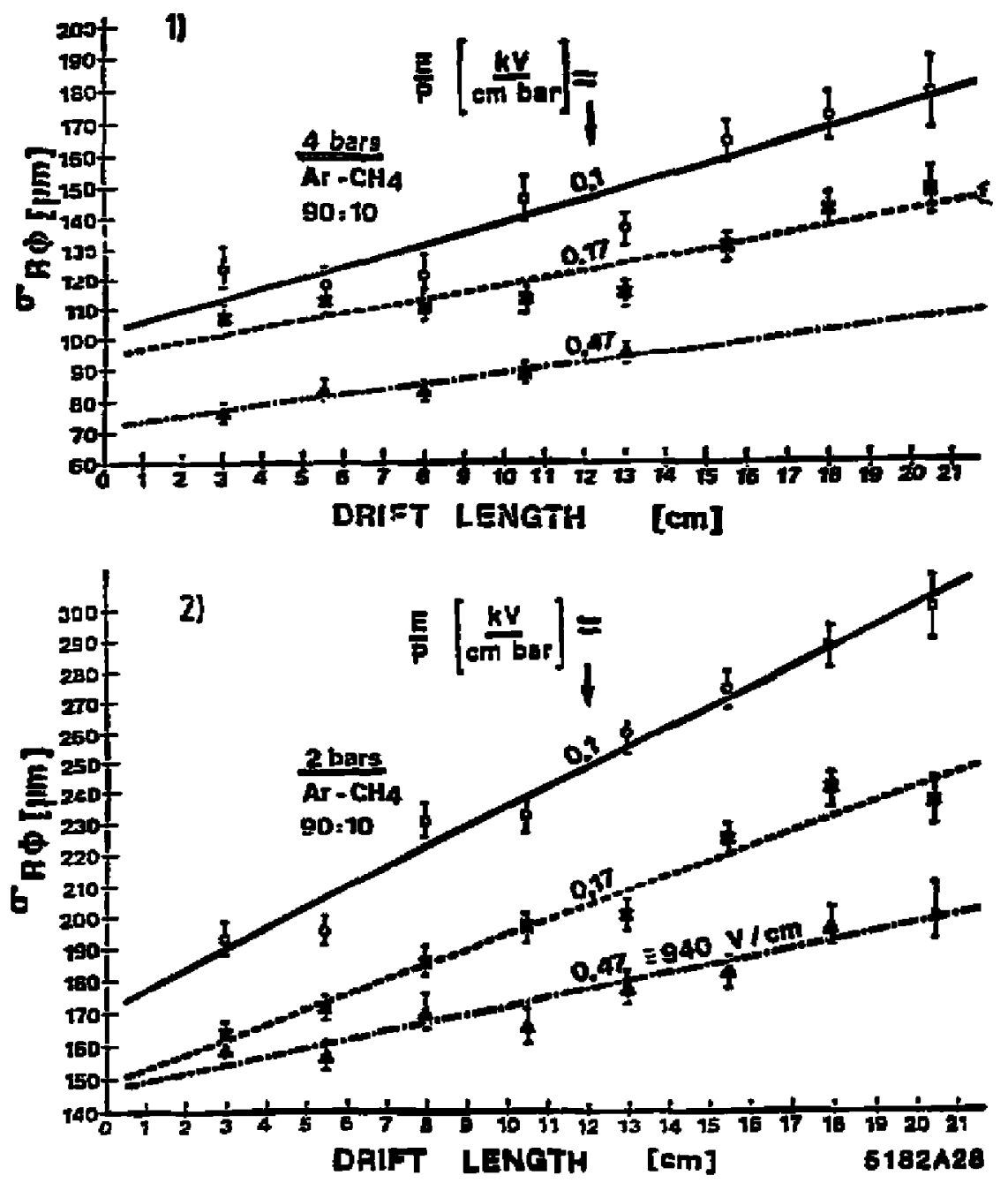

Fig. 25 


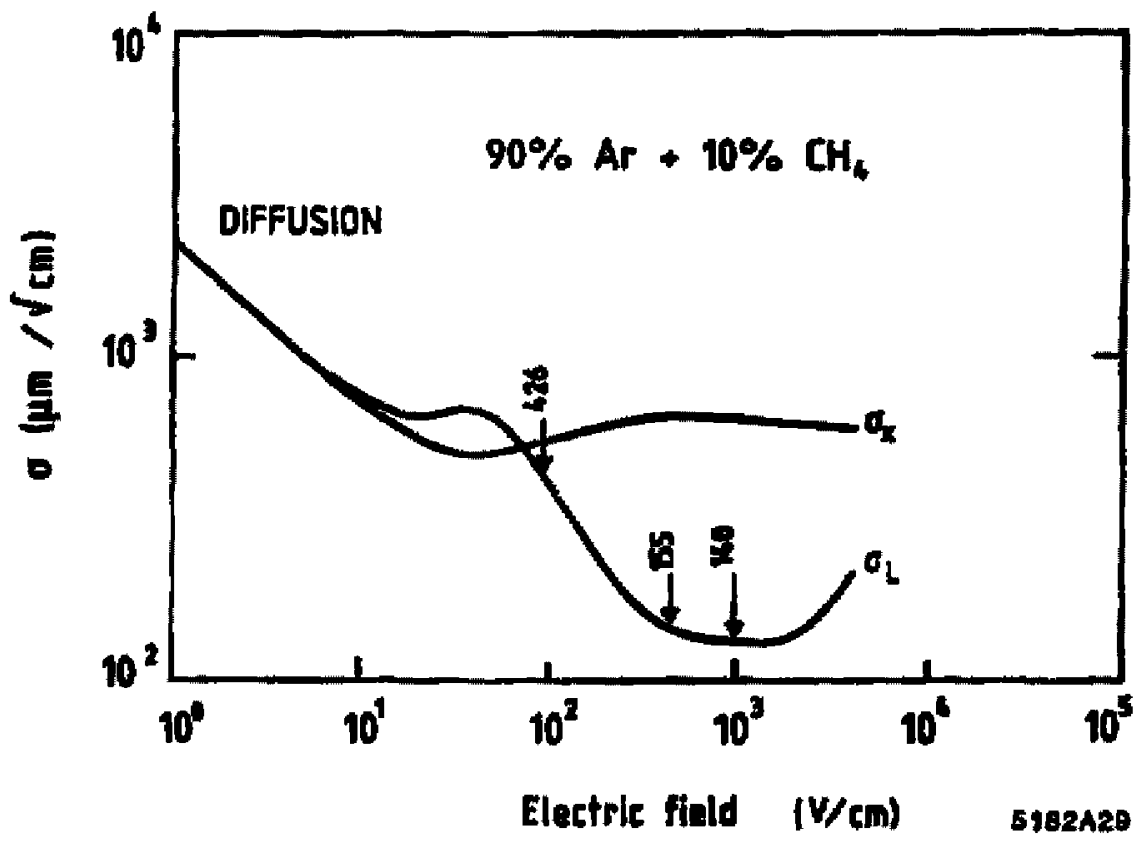

Fig. 26 


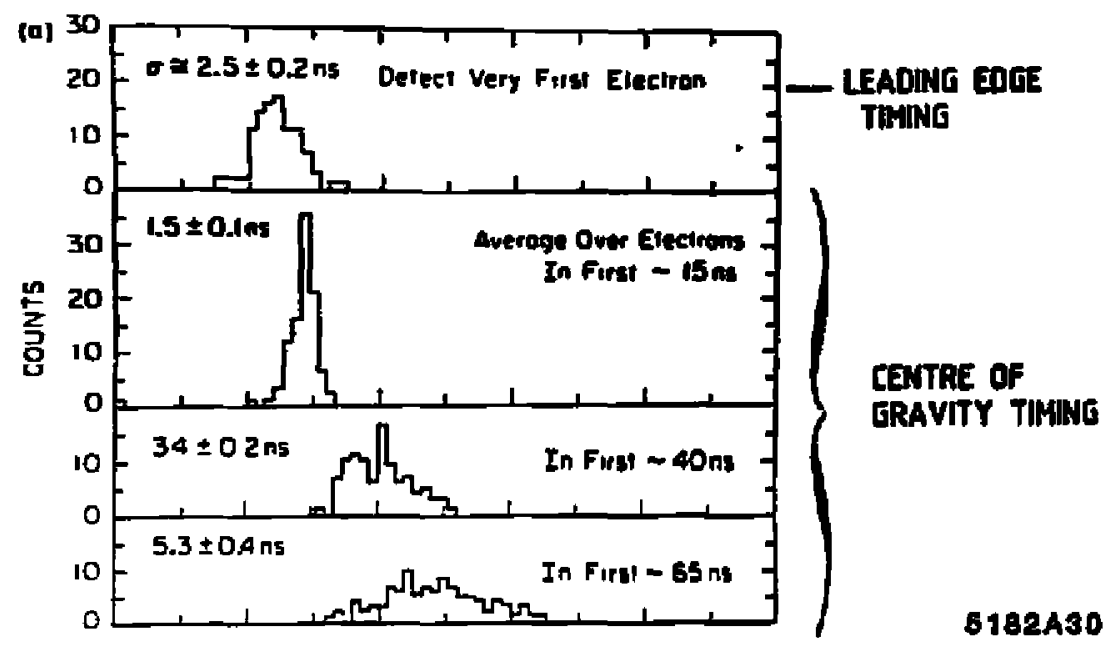

Fig. 27 

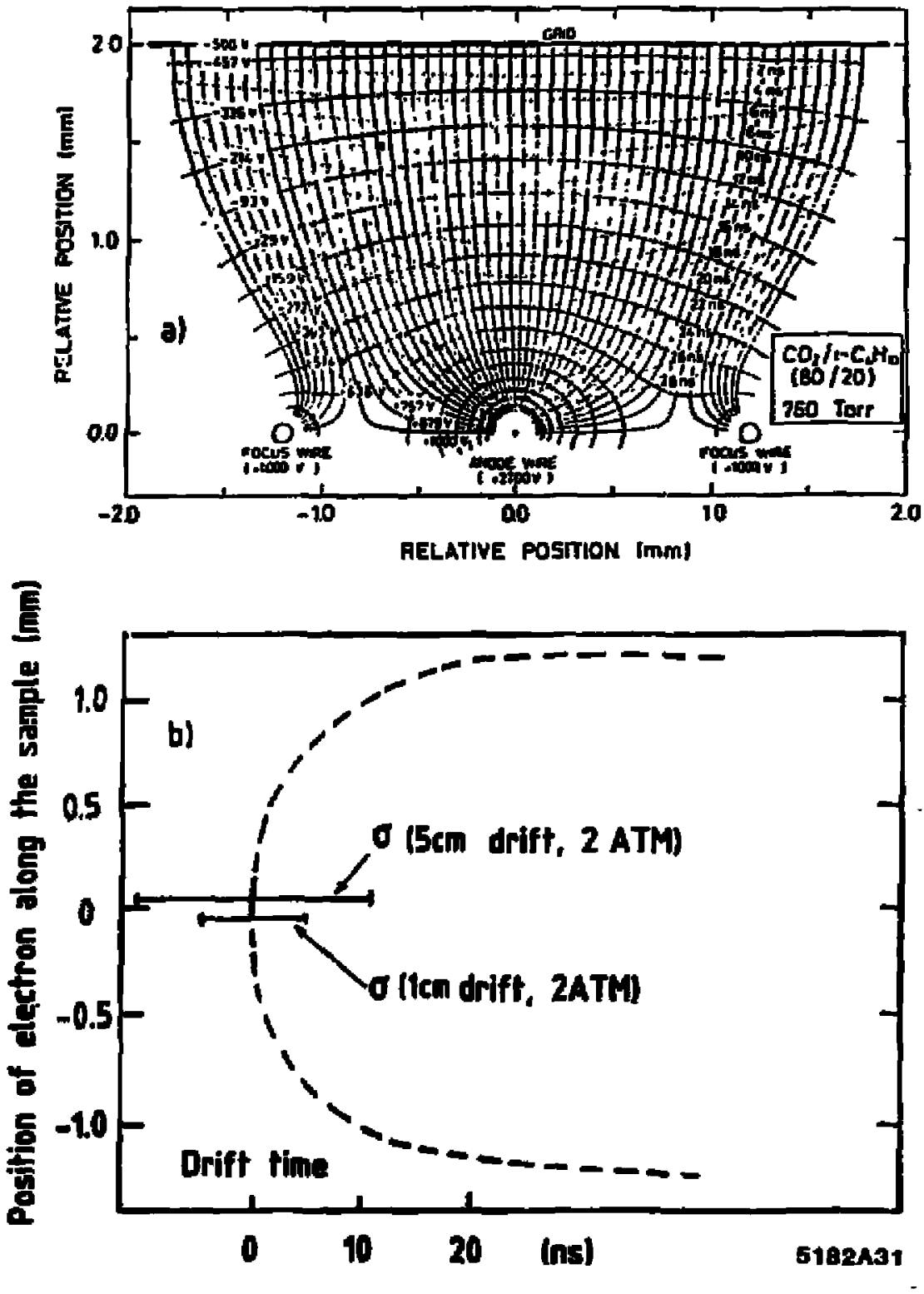

Fig. 28 

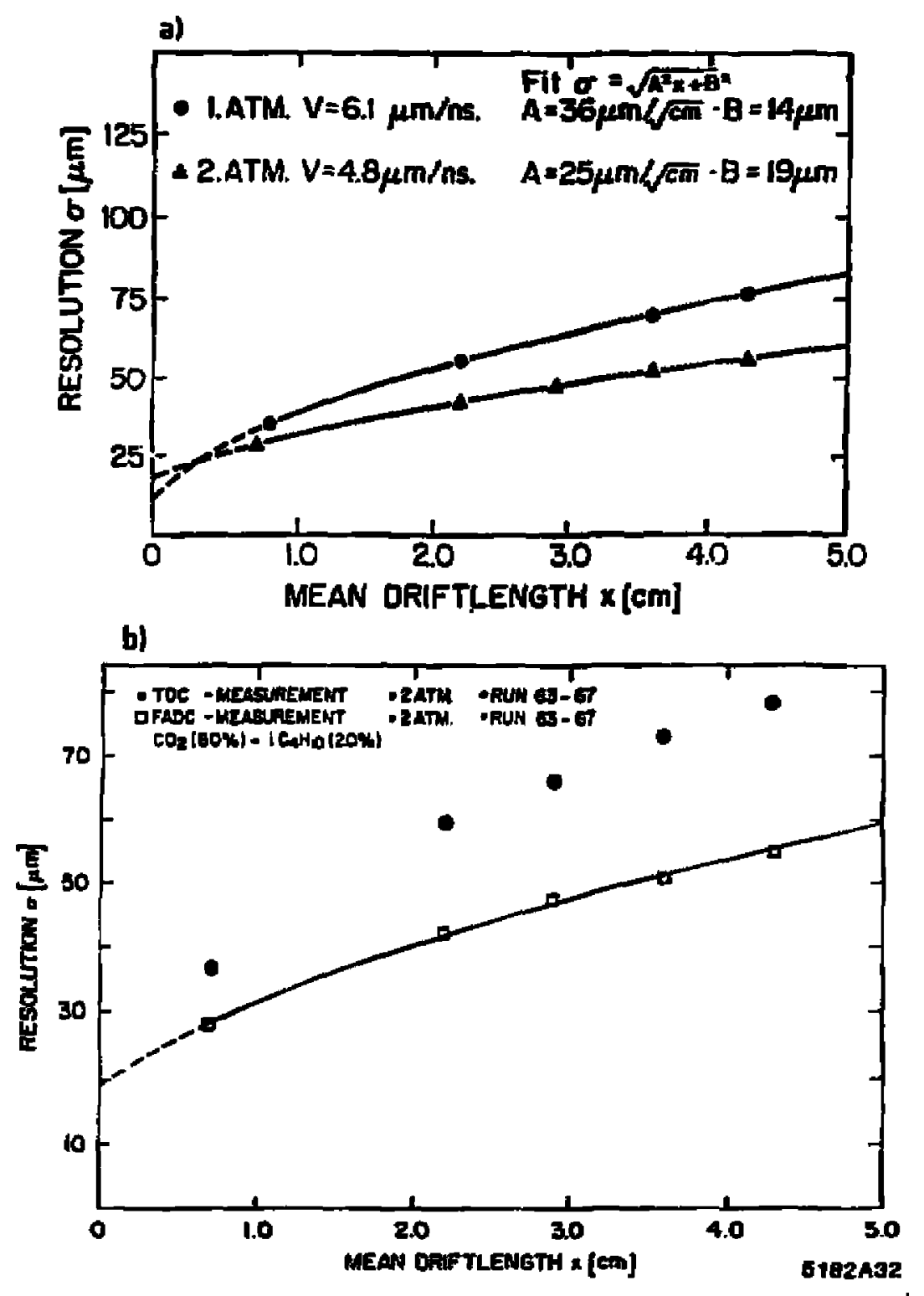

Fig. 29 


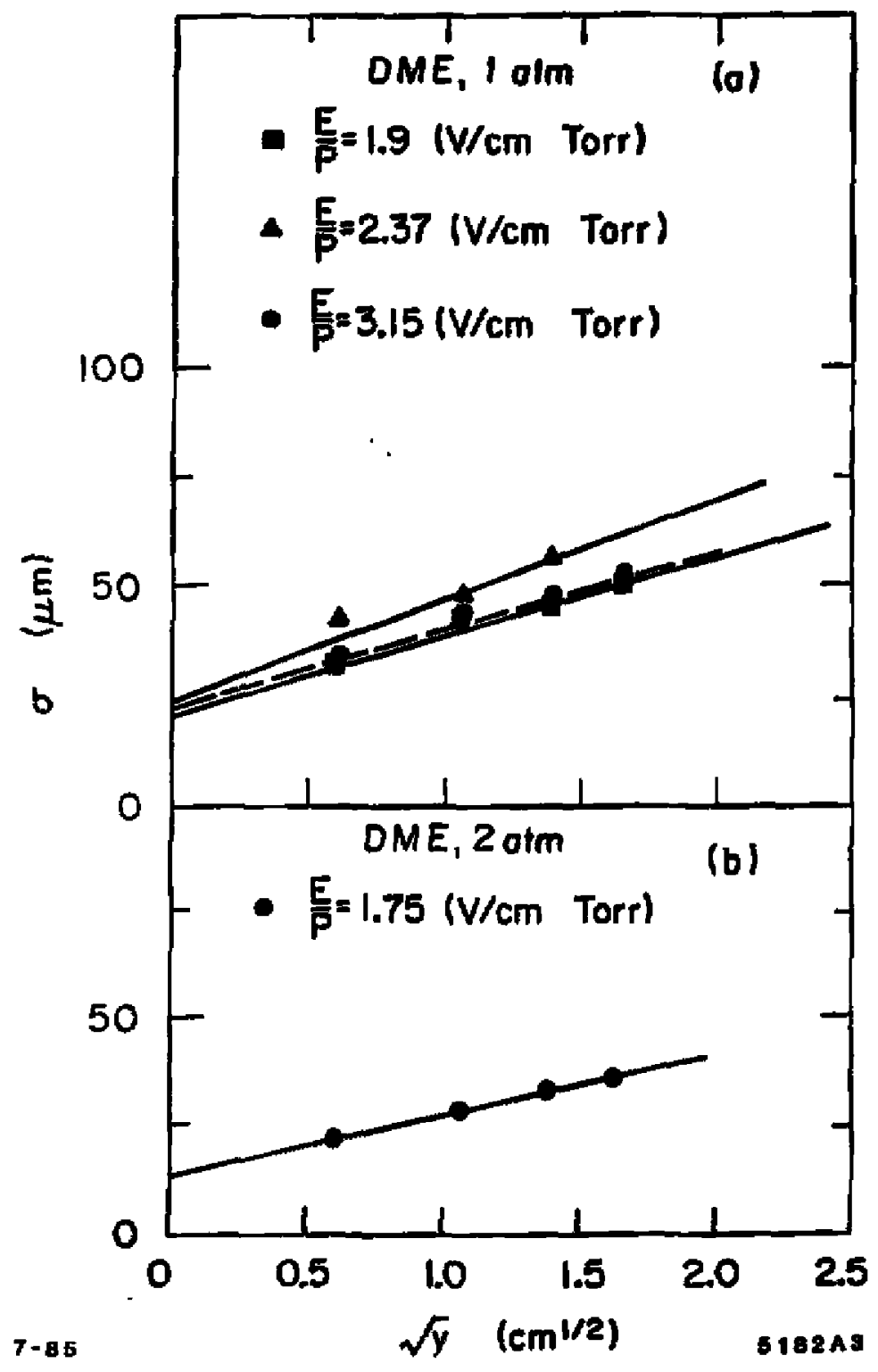

Fig. 30 


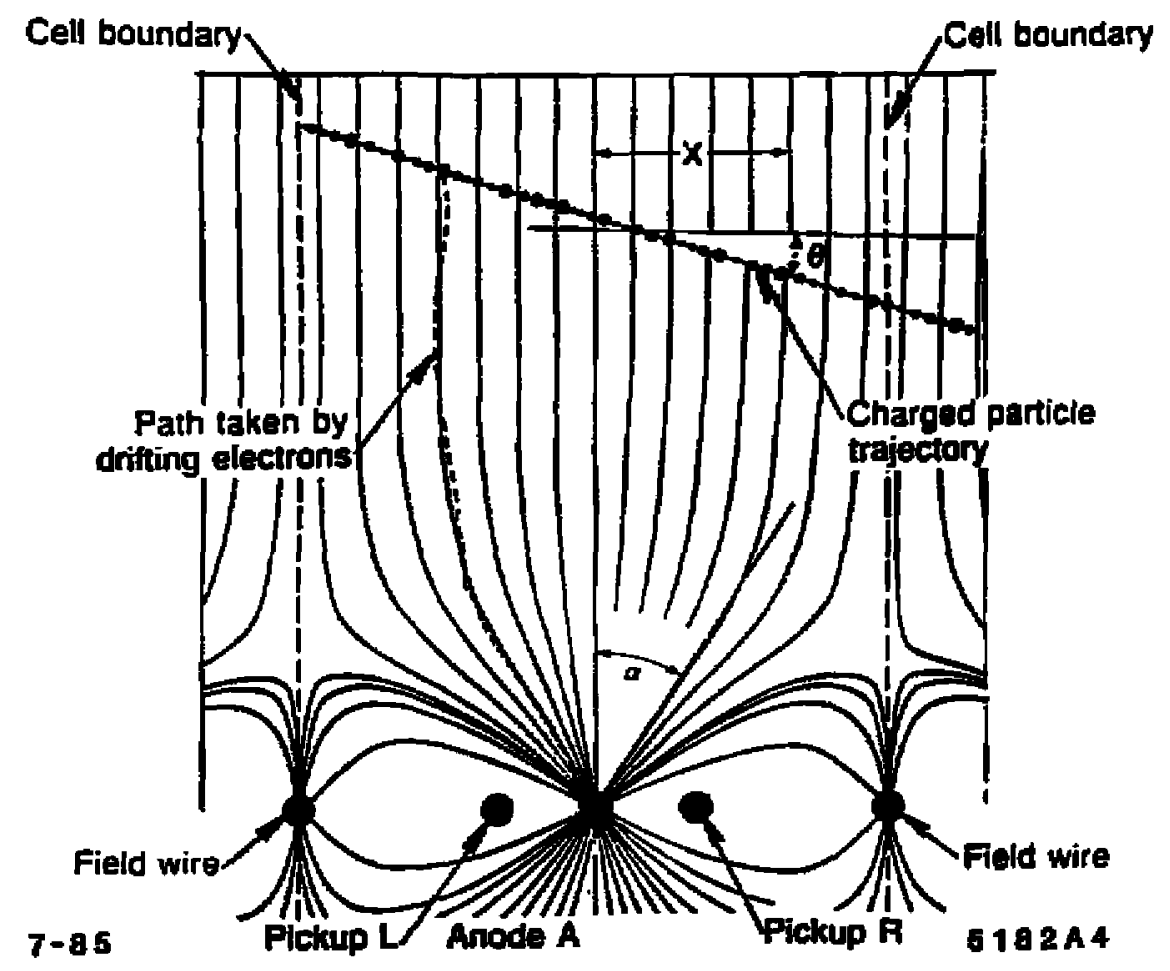

Fig. 31 

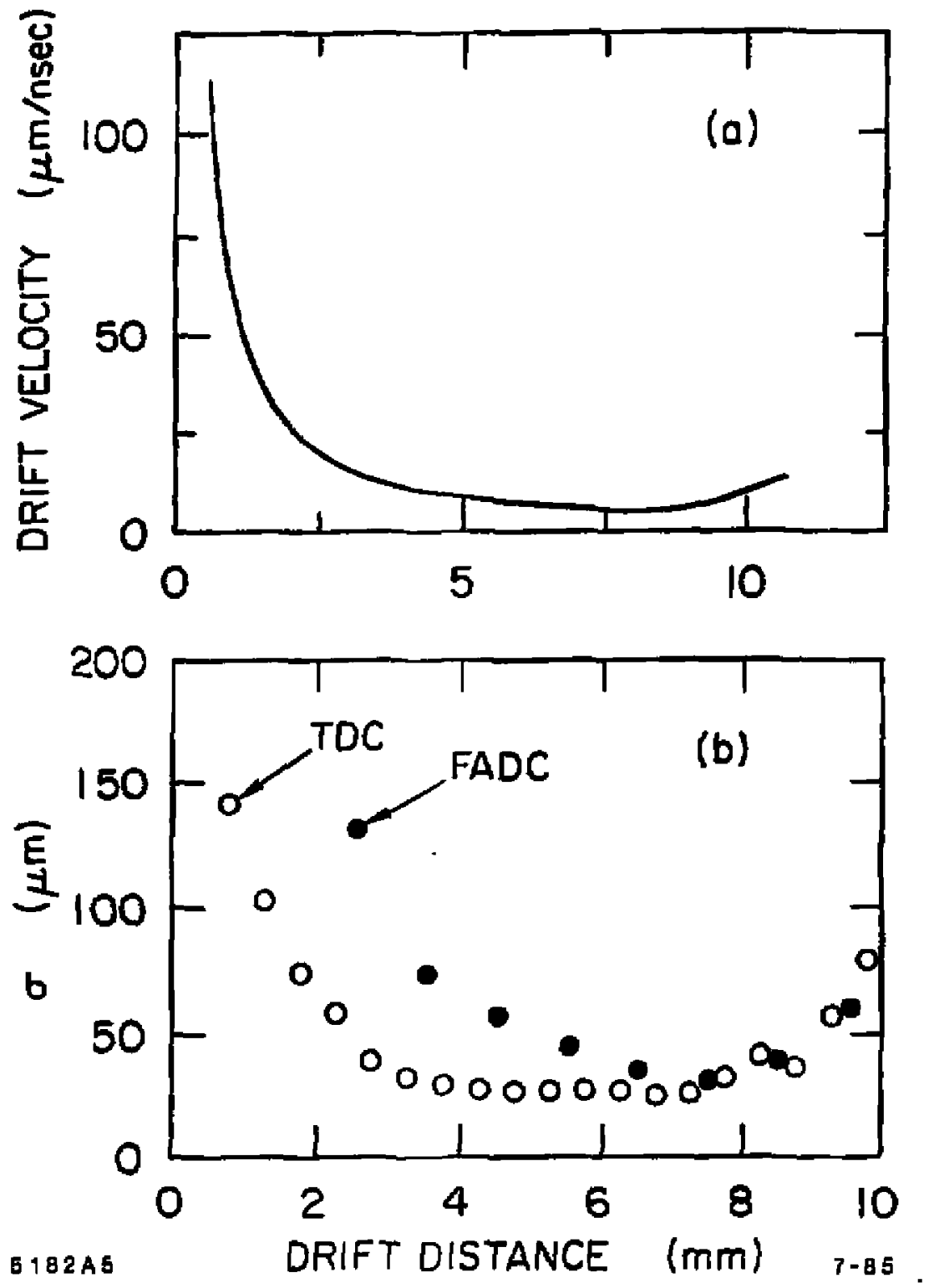

Fig. 32 


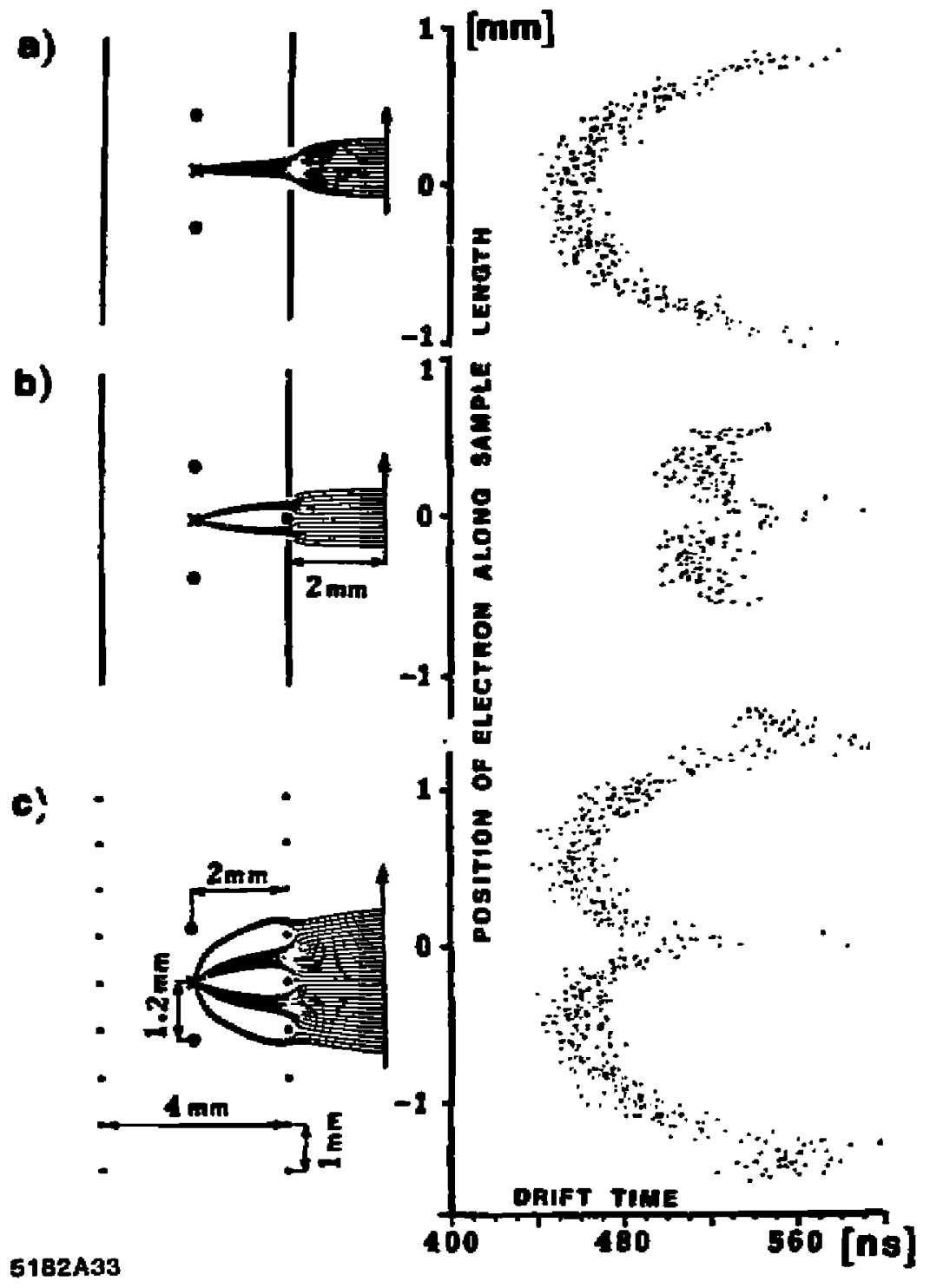

Fig. 33 

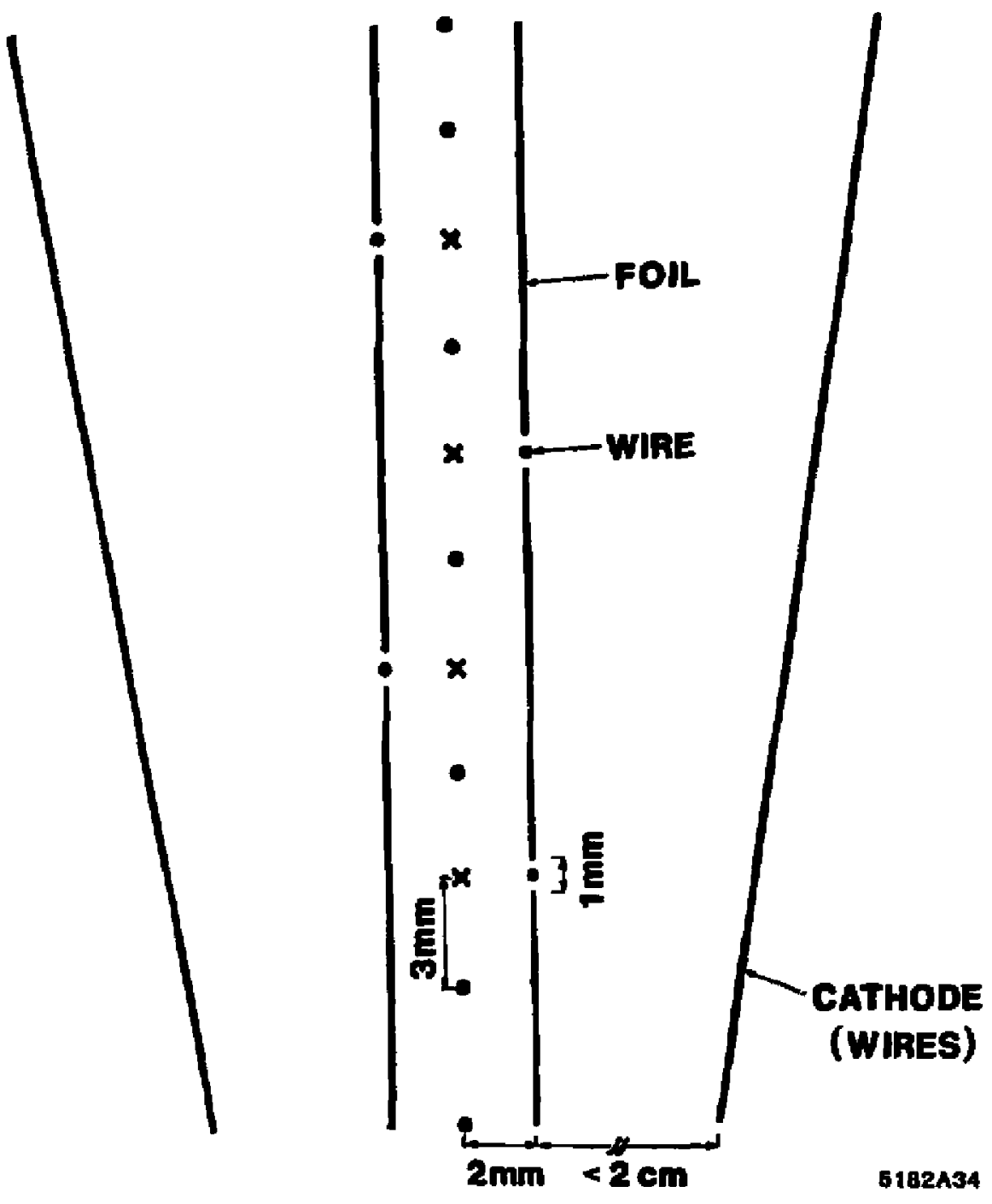

Fig. 34 
$4 \mathrm{~mm}$

a.

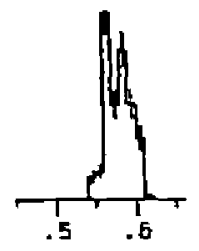

b.

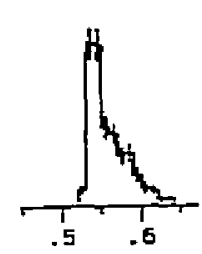

c.
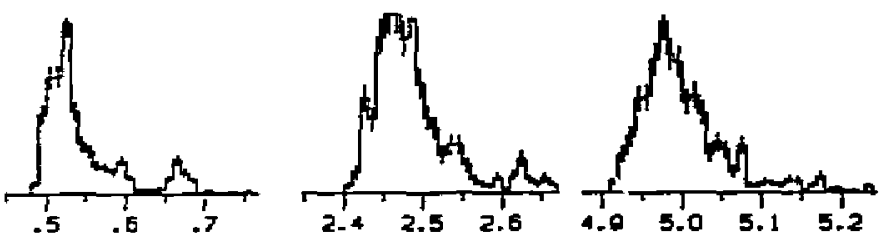

d.

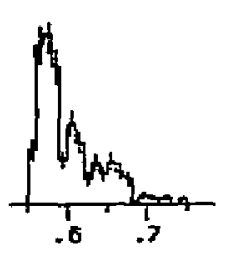

$12 \mathrm{~mm}$

$22 \mathrm{~mm}$
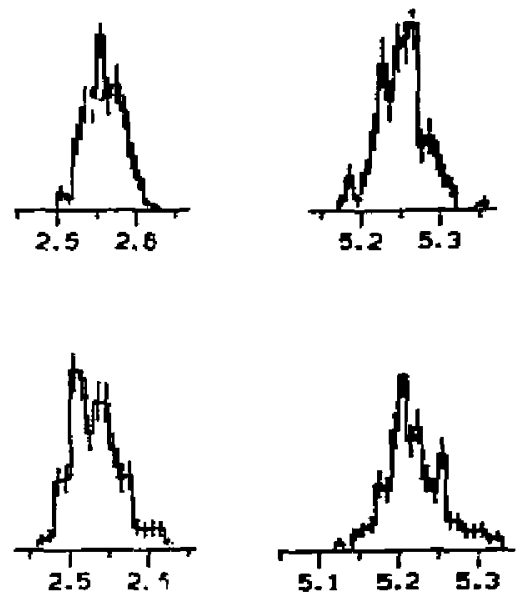

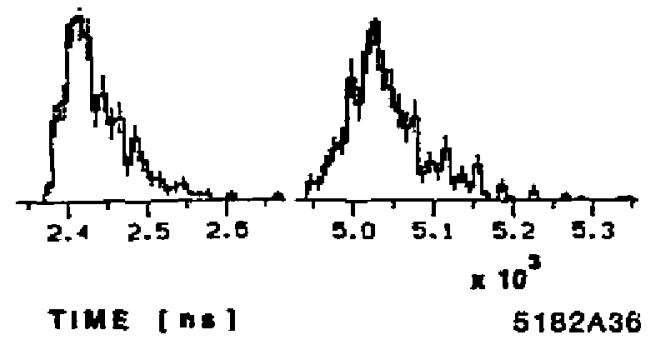

Fig. 35 


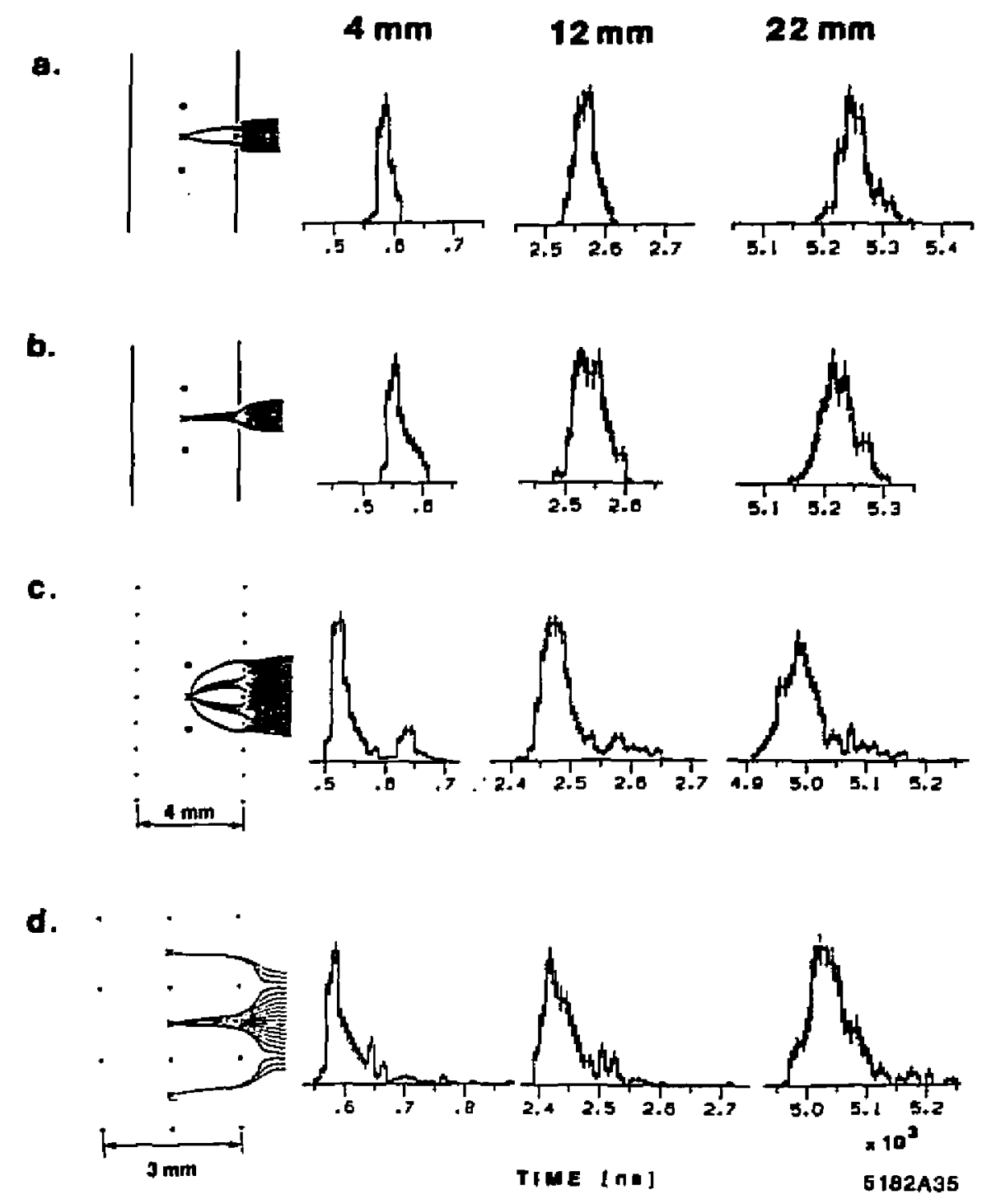

Fig. 36 